\title{
PROPUESTA METODOLÓGICA PARALA CARACTERIZACIÓN TERRITORIAL DEL TURISMO A ESCALA LOCAL
}

\author{
Rafael Merinero-Rodríguez \\ Centro de Sociología y Políticas Locales. Universidad Pablo de Olavide. Sevilla \\ rmerrod@upo.es \\ Juan Ignacio Pulido-Fernández \\ Laboratorio de Análisis e Innovación Turistica (LAInnTUR). Departamento de Economía. Universidad de Jaén \\ jipulido@ujaen.es \\ Clemente Navarro-Yáñez \\ Centro de Sociología y Políticas Locales. Universidad Pablo de Olavide, de Sevilla \\ cnavyan@upo.es
}

\section{RESUMEN}

Existe un creciente interés por el territorio como factor estratégico de desarrollo local. Este interés se nota especialmente en el ámbito del turismo, cuyo desarrollo depende en gran medida de la disponibilidad de recursos basados en los atributos del territorio. Las características de estos recursos permiten la identificación de diferentes ámbitos turísticos, estructurados territorialmente, que son utilizados para la formulación de propuestas de actuación en materia de turismo.

En este trabajo se propone una metodología para la identificación de las tipologías de recursos turísticos, en este caso aplicado a la Comunidad Autónoma Andaluza, como paso previo a la caracterización de sus municipios turísticos en función de dichos recursos.

Palabras clave: territorio, turismo, espacio turístico, recursos turísticos, análisis factorial, análisis cluster.

\section{ABSTRACT}

There is growing interest in the territory as a strategic factor of local development. This interest is particularly evident in the field of tourism, whose development depends largely

Fecha de recepción: noviembre 2012.

Fecha de aceptación: noviembre 2013. 
on the availability of resources based on the attributes of the territory. The characteristics of these resources allow the identification of different tourist areas, structured territorially, which are used for the formulation of policy proposals on tourism.

This paper proposes a methodology for identifying the types of tourism resources, in this case applied to Andalusia, as a step towards characterizing its tourist towns based on these resources.

Key words: territory, tourism, tourist space, tourism resources, factor analysis, cluster analysis.

\section{INTRODUCCIÓN}

Desde finales del siglo pasado se viene poniendo de manifiesto un cambio en el modelo de desarrollo de la actividad turística que ha sido definido como la Nueva Era del Turismo (Fayos-Solas, 1996). En este nuevo marco, una serie de transformaciones (OMT-WTO, 2001, 2002; Pulido y López, 2011), están modificando los procesos de planificación y de gestión, así como las estrategias de promoción y comercialización, pues condicionan, cada vez en mayor medida, la posición competitiva de cualquier destino. Estas transformaciones suponen un cambio de perspectiva que sitúa el principal centro de atención en el territorio. En el modelo clásico del turismo, el territorio adoptaba el papel de mero contenedor de las acciones que impulsaban las empresas (generalmente ajenas al mismo), orientadas a ensamblar en destino los elementos de sus productos turísticos. En el nuevo modelo de turismo, sin embargo, el territorio adquiere un papel activo y clave para articular los procesos de desarrollo turístico, asumiendo que éste se debe de enmarcar en planteamientos de mayor alcance que tienen que ver con su instrumentación en el seno del denominado desarrollo local (Cebrián, 2008; Fernández, 2004; López Palomeque, 1998; Marchena, 1998; Sáez, 2008; Vera et al., 1997; Vera y Antón, 1998; entre otros).

Tal cambio de modelo turístico tiene una incidencia importante en el tipo de política turística que deben formular los diferentes niveles de gobierno y, en el caso de España, especialmente los gobiernos regionales, al ser los principales agentes públicos del desarrollo turístico en el actual marco competencial. Estas adaptaciones en materia de acción pública regional en turismo exigen cambios importantes no sólo en el contenido de las políticas, sino también en las orientaciones estratégicas básicas que implican, en el sentido de la importancia que adquiere el territorio en este nuevo escenario, lo que les obliga a impulsar procesos de gobernanza multinivel en los que estén presentes los gobiernos locales y a incorporar los recursos locales-territoriales a nivel municipal como componente fundamental de las actuaciones turísticas que se han de plantear (Aas, Ladkin y Fletcher, 2005; Bramwell y Lane, 1999; Lazzaretti y Petrillo, 2006; Merinero, 2009; Michael, 2007; Pforr, 2006; Selin y Chavez, 1995; Vernon, Essex, Pinder y Curry, 2005).

Estas cuestiones están en proceso de incorporación a la agenda política de los gobiernos regionales españoles. En una primera etapa, con el traspaso de las competencias del Estado a las Comunidades Autónomas, la agenda política regional de turismo estuvo especialmente centrada en la creación de las estructuras y los procesos administrativos fundamentales orientados a la regulación de la actividad y a la promoción turística (Aguiló, 1998; Bote y Mar- 
chena, 1996; Marchena, 1989; Pearce, 1997). En los últimos años, se están produciendo cambios importantes en las características de las políticas turísticas regionales, que van en el sentido anteriormente indicado, y en los que se puede apreciar el «efecto territorialización» que caracteriza al nuevo modelo de turismo (Antón y Duro, 2009; Granados, 2008; López y López, 2008; Valenzuela, 2008).

El objetivo de la investigación cuyos resultados se exponen seguidamente es el de generar un modelo de análisis del denominado sistema turístico regional, aplicándolo al caso de Andalucía. El artículo se centra, por tanto, en la descripción del proceso metodológico de operacionalización de dicho modelo analítico y su aplicación para identificar las características del sistema turístico de la región a través de los ámbitos territoriales especificados en el Plan General de Turismo Sostenible de Andalucía (2008-2011) (en adelante, PGTS).

El artículo se estructura en cinco apartados, además de esta introducción. En el siguiente apartado se analiza la función estratégica del territorio en los procesos de desarrollo turístico y el papel clave que han ido adquiriendo los recursos turísticos locales en la articulación de las estrategias de desarrollo turístico de las regiones españolas. El tercer apartado resume el proceso metodológico seguido para la consecución de los objetivos propuestos en este artículo. Los resultados obtenidos se presentan y analizan en el apartado cuarto, dedicándose el quinto a la caracterización de los municipios turísticos andaluces a partir de los resultados anteriores. Las principales conclusiones obtenidas se presentan en el sexto apartado.

\section{LA FUNCIÓN ESTRATÉGICA DEL TERRITORIO Y SU CONCRECIÓN EN LAS ESTRATEGIAS REGIONALES DE TURISMO EN ESPAÑA}

El consumo turístico requiere necesariamente el desplazamiento del lugar de residencia habitual a otro en el que disfrutar una experiencia relacionada con las motivaciones del turista. El espacio es, por tanto, un factor clave para el desarrollo turístico. Según Cebrián (2010: 363), «hay que asumir el indiscutible papel que ocupa el territorio en una doble dimensión: como soporte de recursos y como recurso en sí mismo». Por ello, de acuerdo con Troitiño (1999), es necesaria una nueva interpretación del territorio, superando la concepción de mero soporte de la actividad económica, para entenderlo como un recurso de múltiples dimensiones e interdependencias. Sin embargo, a pesar de ello, el tradicional predominio de la dimensión económica de la actividad turística ha obviado hasta hace poco esta cuestión. Incluso, como plantean Vera et al. (2011), la dificultad para vincular el turismo con el medio geográfico ha disipado hasta muy recientemente el interés de los geógrafos por estas cuestiones.

Se conceptualiza el espacio turístico como el territorio en el cual se ubican los elementos relacionados con la actividad turística: los recursos susceptibles de ser convertidos en productos turísticos, las infraestructuras de acceso y apoyo a la actividad turística, los alojamientos y el espacio en el que se desarrollan las actividades (Vera et al., 2011). En general, la caracterización de espacios turísticos puede fundamentarse en múltiples criterios y variables, si bien, la mayoría de estudios establecen cuatro aspectos básicos: motivacional, social, espacial y temporal.

Una revisión bibliográfica permite destacar las aportaciones de Lew (1987), que considera tres tipos de medios: un medio natural, un medio humanizado y un medio intermedio, de contacto entre el medio natural y el humanizado. Por su parte, Williams y Shaw (1990) 
plantean la necesidad de identificar las motivaciones de los turistas, su localización territorial y los ámbitos espaciales en los que se manifiestan las actividades. Vera et al. (1997) distinguen, en una clasificación básica, entre cuatro tipos de entornos geográficos: espacios litorales, espacios urbanos, espacios rurales y espacios naturales. Estos autores plantean una serie de criterios a tener en cuenta a la hora de identificar y caracterizar los espacios turísticos, destacando la consideración del recurso en el que se basa la actividad turística y la condición geográfica del espacio. De hecho, como reconoce López Olivares (1998), son estas dos variables las que favorecen la diferenciación de los entornos geográficos como facilitadores y contenedores de prácticas turísticas.

Por otra parte, como señalan Barrado y Sáez (2008: 463), «el turismo como sector económico vende servicios construidos en torno a los recursos puestos en valor». En consecuencia, la identificación y segmentación de los recursos de un territorio es clave para una adecuada planificación y posterior gestión turística de cualquier territorio. Los recursos turísticos son la base sobre la que se desarrolla la actividad turística y están fundamentados en los atributos del territorio (Leno, 1993). De ahí la necesidad de disponer de herramientas y metodologías que faciliten la identificación y caracterización de los recursos de un territorio susceptibles de uso turístico.

Lo expuesto hasta ahora permite destacar la importancia del territorio como fundamento del turismo. Esta importancia no es una novedad. Por supuesto que el territorio ha desempeñado siempre un papel clave en el reforzamiento de la identidad de cualquier destino turístico (Valenzuela, 1986). Lo que ocurre es que, hasta muy recientemente, los conocidos como policymakers, más preocupados por los aspectos económicos de la actividad turística, no habían asumido sus implicaciones espaciales.

En los últimos años, sin embargo, la relación entre territorio, turismo y desarrollo ha abierto un campo de investigación en torno al estudio del territorio como factor de desarrollo a escala local (Monteseirín, 2008), centrando el interés de los investigadores en la función estratégica que desempeña el territorio y su nueva conceptualización en el marco de los procesos de desarrollo.

No en vano, como recuerdan Barrado y Ávila (2005: 33), «uno de los grandes retos de cualquier proyecto de desarrollo turístico sería aunar diferentes sectores productivos en un mismo marco territorial para crear sinergias entre todos los componentes y sectores económicos, lo cual en muchas ocasiones choca de frente con la desestructuración de gran parte de los espacios turísticos o potencialmente turísticos, especialmente en el interior». En consecuencia, el espacio turístico se convierte en centro de atención de la política territorial, que empieza a plantearse estas cuestiones más allá de la mera intervención espacial, sino que debe responder a la necesidad de consolidar un desarrollo innovador, creativo e inteligente (Comisión Europea, 1999).

Este «efecto territorialización», que Barrado (2011: 46) explica que es consecuencia de la modificación morfológica del territorio que se produce cuando «una actividad o sector [...] lo convierte en factor y recurso de producción y en espacio productivo y/o de consumo», se ha podido comprobar también en las nuevas leyes de turismo que se han impulsado por un buen número de gobiernos regionales en España en los últimos años y en el contenido de algunos planes de desarrollo turístico de ámbito regional que están poniendo en marcha algunos de esos gobiernos. 
Esta territorialización de la política turística regional ${ }^{1}$, que se puede apreciar en la normativa y en las propuestas de desarrollo turístico de los diferentes planes de turismo que proponen las Comunidades Autónomas, se concreta en el papel fundamental que adquieren los recursos turísticos locales (la escala local) para la articulación de las estrategias de desarrollo turístico de dichas regiones. Esta circunstancia se traduce en la identificación de diferentes ámbitos turísticos, estructurados territorialmente, que están configurados a nivel de los municipios. Estos ámbitos, que son utilizados para la formulación de propuestas de actuación en materia de turismo, han venido denominándose de diferente forma (sistemas turísticos locales, sistemas turísticos regionales, ámbitos geográficos de actuación turística, etc.). En este trabajo, se ha optado por la denominación de sistema turístico regional, entendiendo como tales los tipos de ámbitos geográficos de una Comunidad Autónoma configurados sobre la base de las características de los recursos turísticos que se presentan a escala local-municipal.

Un sistema turístico regional es, por tanto, la estructura territorial de la oferta de recursos turísticos a nivel municipal de una determinada Comunidad Autónoma. En consecuencia, este concepto, que se utiliza con diferentes denominaciones en la reciente normativa turística de las Comunidades Autónomas y en los planes de desarrollo turístico de las mismas, es la respuesta de la política turística regional española al protagonismo que adquiere el territorio en el nuevo paradigma de planificación y gestión turística. Sin embargo, el tratamiento de concepto en los documentos de política regional antes descritos es muy limitado en su caracterización, por lo que es necesario impulsar nuevos modelos de análisis que tengan la capacidad de aprehender los elementos clave de los diferentes ámbitos en los que se estructuran dichos sistemas turísticos regionales.

Esta circunstancia convierte a la investigación turística en un elemento a incorporar en la agenda política, ya que, para que los ámbitos geográficos locales adquieran toda su funcionalidad como instrumento de desarrollo turístico regional, es imprescindible avanzar en instrumentos analíticos que permitan su caracterización lo más completa y avanzada posible, para, a partir de ello, poder ser utilizados en la planificación y la política turística a nivel regional.

\section{ENFOQUE METODOLÓGICO}

A continuación, se explicita el proceso metodológico seguido para identificar las tipologías de recursos turísticos, en este caso aplicado a la Comunidad Autónoma Andaluza, como paso previo a la caracterización de sus municipios turísticos en función de dichos recursos.

El trabajo realizado (Figura 1) desarrolla un modelo de inventario, segmentación y caracterización de recursos turísticos a nivel local, utilizando un doble análisis factorial (de componentes principales). Una vez identificadas las tipologías de recursos turísticos existentes en Andalucía, a través del análisis cluster, se procede a una clasificación de los municipios andaluces en función de la/s tipología/s de recursos en que están especializados y a la caracterización general de cada uno de los conglomerados obtenidos.

1 La territorialización de la política regional de turismo se puede comprobar en la aplicación de la denominada gobernanza multinivel y en la importancia que tiene la articulación de las estrategias turísticas a través de los recursos locales de la región que existen en el ámbito municipal. En este trabajo sólo se va a analizar el segundo de los temas, la propuesta de gobernanza multinivel no va a ser analizada. 


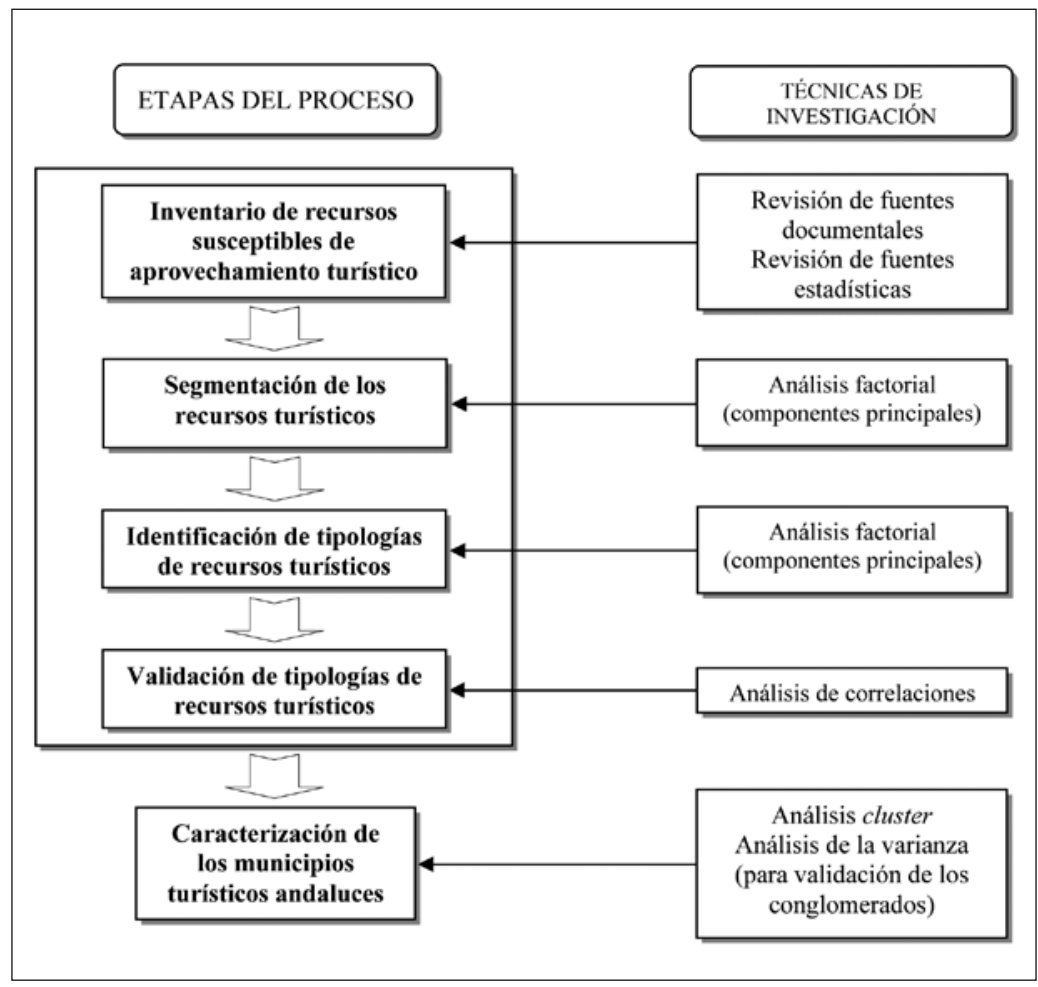

Fuente: Elaboración propia.

\section{PRESENTACIÓN Y ANÁLISIS DE RESULTADOS}

Seguidamente, se presentan los resultados obtenidos tras la aplicación de la metodología anteriormente propuesta, concluyendo con la identificación y validación de las tipologías de recursos turísticos previas a la caracterización de los municipios turísticos andaluces, que se realiza ya en el apartado quinto.

\section{Identificación de los recursos turísticos}

Tanto por su extensión territorial, como por su riqueza natural y patrimonio histórico y cultural, la región andaluza concentra en su territorio innumerables recursos que le otorgan una posición destacada en el mercado turístico nacional e internacional. Sin embargo, el grado de aprovechamiento de los mismos, así como las condiciones en que se encuentran para su puesta en valor y, en su caso, su uso público, son muy diversas (Junta de Andalucía, 2007).

El proceso de análisis de los recursos turísticos de los municipios andaluces que se desarrolla en el presente trabajo tiene como punto de partida los grupos de recursos turísticos 
definidos en el PGTS (frente litoral, paisajes naturales, patrimonio histórico y cultural, fiestas y costumbres y «estilo de vida»; aunque este último ha sido excluido del análisis por la dificultad que supone su tratamiento y por no ser éste el tema objeto de este estudio). Para su operacionalización, se ha llevado a cabo una búsqueda extensiva de variables disponibles en fuentes documentales y estadísticas de diversa naturaleza. Cabe resaltar en este punto la dificultad que ha supuesto recabar información sobre recursos turísticos por municipio, dada la escasez de fuentes que facilitan datos con desagregación municipal.

Recopilada la información relativa a los recursos turísticos (553 variables, procedentes de 15 fuentes documentales y 20 bases de datos diferentes), se procedió a la selección de aquellas que presentaban una relación directa con los grupos de recursos que se pretendían representar, con el fin de ganar en operatividad para después agruparlas en lo que se ha denominado segmentos turísticos teóricos, que coinciden con los segmentos de recursos turísticos definidos en el PGTS. Así pues, la operacionalización del análisis de los datos se resume en las Tablas 1 y 2.

Tabla 1

VARIABLES PARA EL ANÁLISIS DE LOS RECURSOS NATURALES Y PATRIMONIALES

\begin{tabular}{|c|c|c|c|}
\hline \multicolumn{2}{|c|}{$\begin{array}{c}\text { GRUPOS DE } \\
\text { RECURSOS TURÍSTICOS }\end{array}$} & $\begin{array}{c}\text { SEGMENTOS } \\
\text { TURÍSTICOS } \\
\text { TEÓRICOS } \\
\end{array}$ & VARIABLES \\
\hline \multirow{8}{*}{ NATURALES } & \multirow{4}{*}{$\begin{array}{l}\text { FRENTE } \\
\text { LITORAL }\end{array}$} & \multirow{2}{*}{ SOL Y PLAYA } & Total_playas \\
\hline & & & Presencia_litoral \\
\hline & & \multirow{2}{*}{ NÁUTICO } & Total_puertos deportivos \\
\hline & & & Total_estaciones náuticas \\
\hline & \multirow{4}{*}{$\begin{array}{c}\text { PAISAJES } \\
\text { NATURALES }\end{array}$} & \multirow[b]{2}{*}{ NATURALEZA } & Total_Espacios Naturales Protegidos por tipo \\
\hline & & & $\begin{array}{l}\text { Total_Equipamientos de uso público de los } \\
\text { EENNPP por tipo }\end{array}$ \\
\hline & & SALUD Y BELLEZA & Total_balnearios \\
\hline & & DEPORTE & Total_Espacios deportivos por tipo \\
\hline \multirow{9}{*}{ PATRIMONIALES } & \multirow{9}{*}{$\begin{array}{c}\text { PATRIMONIO } \\
\text { HISTÓRICO Y } \\
\text { CULTURAL }\end{array}$} & $\begin{array}{l}\text { CULTURAL } \\
\text { HISTÓRICO }\end{array}$ & Total_Bienes Inmuebles Protegidos \\
\hline & & $\begin{array}{l}\text { CULTURAL } \\
\text { ARTÍSTICO }\end{array}$ & Total_Museos por tipos \\
\hline & & \multirow{5}{*}{$\begin{array}{l}\text { CULTURAL } \\
\text { RECREATIVO }\end{array}$} & Total_bibliotecas públicas \\
\hline & & & Aforo_cines \\
\hline & & & Aforo_recintos escénicos \\
\hline & & & $\begin{array}{l}\text { Total_Establecimientos de comercio al por } \\
\text { menor por tipos }\end{array}$ \\
\hline & & & $\begin{array}{l}\text { Total_Establecimientos de ocio y } \\
\text { espectáculos por tipos }\end{array}$ \\
\hline & & $\begin{array}{l}\text { FIESTAS Y } \\
\text { COSTUMBRES }\end{array}$ & Total_Fiestas de interés turístico por tipos \\
\hline & & REUNIONES & Total_Palacios de congresos \\
\hline
\end{tabular}

Fuente: Elaboración propia. 
Tabla 2

VARIABLES PARA EL ANÁLISIS DE LOS RECURSOS COMUNES

\begin{tabular}{|c|c|c|}
\hline $\begin{array}{c}\text { GRUPOS DE } \\
\text { RECURSOS } \\
\text { TURÍSTICOS }\end{array}$ & $\begin{array}{c}\text { SEGMENTOS } \\
\text { TURÍSTICOS TEÓRICOS }\end{array}$ & VARIABLES \\
\hline \multirow{5}{*}{$\begin{array}{l}\text { RECURSOS } \\
\text { COMUNES }\end{array}$} & ALOJAMIENTO & $\begin{array}{l}\text { Total_Plazas en hoteles, hostales, pensiones y } \\
\text { apartamentos por tipo (categoría) }\end{array}$ \\
\hline & RESTAURACIÓN & $\begin{array}{l}\text { Total_Plazas en restaurantes y cafeterías por tipo } \\
\text { (categoría) }\end{array}$ \\
\hline & \multirow{2}{*}{ INFORMACIÓN TURÍSTICA } & Total_Oficinas de turismo \\
\hline & & Total_Páginas web turísticas de titularidad pública \\
\hline & $\begin{array}{l}\text { ASOCIACIONES } \\
\text { RELACIONADAS } \\
\text { CON EL TURISMO }\end{array}$ & Total_Asociaciones relacionadas con el turísmo \\
\hline
\end{tabular}

Fuente: Elaboración propia.

Es innegable que Andalucía es una de las regiones con más potencial turístico de nuestro país, aunque el aprovechamiento de sus recursos presenta una distribución bastante irregular. Hasta ahora, se han definido en la región andaluza tres grandes ámbitos territoriales turísticos: el litoral, el urbano de interior y el rural de interior (Junta de Andalucía, 2007: 42). El ámbito territorial de litoral está directamente ligado a un recurso exclusivo y característico, como es la presencia de zona costera, pero, en lo relativo a los ámbitos de interior, tanto urbano como rural, conviene puntualizar que su operacionalización se ha llevado a cabo en función de la mayor presencia de un recurso turístico u otro, puesto que tanto aquellos relacionados con la riqueza natural o paisajística, como con el patrimonio histórico y cultural, están presentes en los tres ámbitos mencionados.

Por otra parte, existen otro tipo de variables -no exactamente recursos, aunque se ha optado por denominarlos así; en algunos casos son servicios y en el otro se trata de asociaciones-, comunes a todos los segmentos, cuyo análisis se ha utilizado para la validación de los segmentos turísticos empíricos. Se trata concretamente del alojamiento, representado por el número total de plazas o camas, por tipo de establecimiento; la restauración, recogida también por total de plazas en restaurantes y cafeterías; la información turística, de la cual se ha considerado la versión más tradicional, esto es, el total de oficinas de turismo por municipio, así como el número de webs turísticas de titularidad pública; y, por último, se incluyen el total de asociaciones relacionadas con el turismo, seleccionadas según las categorías en que se encuentran clasificadas en el Registro de Asociaciones de Andalucía (Consejería de Justicia y Administración Pública).

\section{Segmentación de los recursos turísticos}

Una vez descritas las variables utilizadas para analizar el potencial del desarrollo turístico de los municipios de la región andaluza, a continuación se elabora una serie de indicadores 
sintéticos de potencialidad turística, que permitirán definir posteriormente una tipología de recursos turísticos. Para ello, se aplicará el análisis factorial a cada uno de los segmentos de recursos turísticos teóricos descritos anteriormente, con el fin de comprobar si, dada la relación que existe entre las variables que recogen la información relativa a los mismos, es posible reducirlas en número, para así ganar en significación y capacidad de representación.

\section{Análisis factoriales para los indicadores específicos de potencialidad turística}

Dado el elevado número de variables propuestas para representar los segmentos de recursos turísticos que se han considerado teóricos, y comprobada la existencia de correlaciones entre las mismas, se ha optado por la realización de análisis factoriales por grupos de variables, con el fin de reducirlas en número (se han aplicado la medida de adecuación muestral de Kaiser-MeyerOlkin y la prueba de esfericidad de Bartlett, que demostraron la idoneidad de aplicación de la técnica de análisis factorial). Dicha operación posibilitará una ganancia en significación de los resultados, a costa de una mínima pérdida de información, pues, a través de la interpretación de las interrelaciones que existen entre las variables, será posible definir otras, denominadas factores, que, pese a ser menos numerosas, darán cuenta de la estructura subyacente de los recursos turísticos de los municipios andaluces. Así pues, se parte de un conjunto de 42 variables, agrupadas, a priori, en siete segmentos de recursos turísticos teóricos, como se refleja en la Tabla 3.

En general, aquellas variables para las que se disponía de información detallada de la cantidad total por tipos (museos, bienes de interés cultural, fiestas de interés turístico, espacios naturales protegidos y equipamiento de uso público de espacios naturales protegidos), se ha optado por calcular un indicador por sumatorio de cada una de ellas, con el fin de facilitar los análisis (se han llevado a cabo análisis factoriales previos que han puesto de manifiesto que, aunque en primera instancia no se agrupan en un único factor, al serles aplicados nuevos análisis para la obtención de los segmentos empíricos, éstas si entraban a formar parte del mismo factor). Sin embargo, no ha sido éste el caso de las variables que hacen referencia a los recursos turísticos relacionados con el deporte, más concretamente los espacios deportivos, pues análisis factoriales previos han puesto en evidencia la formación de dos factores diferentes y muy significativos a la hora de definir los segmentos de recursos turísticos empíricos. Algo parecido ha sucedido con las variables que recogen información sobre los establecimientos de comercio al por menor y los recreativos y de ocio. Es por ello que, en estos tres últimos casos, se han conservado las variables desglosadas por tipos, en vez de calcular indicadores sintéticos por sumatorio.

En la Tabla 3 se presentan, junto con las variables de partida, los resultados de las pruebas de idoneidad de los análisis factoriales. A continuación, se describen uno a uno los factoriales llevados a cabo, así como los resultados obtenidos al respecto. Cabe señalar que los factores resultantes han sido conservados para posteriores fases del análisis, en forma de puntuación factorial, con el fin de eliminar el efecto negativo de operar con variables medidas en diferentes unidades ${ }^{2}$. Con la misma finalidad, se han calculado las puntuaciones tipificadas en aquellos casos en los que un segmento turístico está representado por una única variable.

2 Las puntuaciones factoriales han sido estimadas con la utilización del método de regresión, por el cual las puntuaciones resultantes tienen de media 0 y varianza igual al cuadrado de la correlación múltiple entre las puntuaciones factoriales estimadas y los valores factoriales verdaderos. 
Tabla 3

VARIABLES INCLUIDAS EN LOS ANÁLISIS FACTORIALES POR SEGMENTOS

\begin{tabular}{|c|c|c|c|c|c|c|}
\hline \multicolumn{7}{|c|}{ ANÁLISIS FACTORIALES POR SEGMENTOS TURÍSTICOS TEÓRICOS } \\
\hline $\begin{array}{l}\text { sol y } \\
\text { playa }\end{array}$ & náutico & $\begin{array}{l}\text { Deporte- } \\
\text { Espacios } \\
\text { deportivos }\end{array}$ & cultural & naturaleza & $\begin{array}{l}\text { salud y } \\
\text { belleza }\end{array}$ & reuniones \\
\hline $\begin{array}{l}\text { Total_ } \\
\text { playas }\end{array}$ & $\begin{array}{l}\text { Total_ } \\
\text { puertos } \\
\text { deportivos }\end{array}$ & $\begin{array}{l}\text { Campos de } \\
\text { fútbol }\end{array}$ & Total_museos & $\begin{array}{l}\text { Total_espacios } \\
\text { naturales } \\
\text { protegidos }\end{array}$ & $\begin{array}{c}\text { Total_ } \\
\text { balnearios }\end{array}$ & $\begin{array}{c}\text { Total_ } \\
\text { palacios de } \\
\text { congresos }\end{array}$ \\
\hline \multirow[t]{10}{*}{ Litoral } & $\begin{array}{l}\text { Total_ } \\
\text { estaciones } \\
\text { náuticas }\end{array}$ & $\begin{array}{l}\text { Pequeños y no } \\
\text { reglamentarios }\end{array}$ & $\begin{array}{l}\text { Total_bienes } \\
\text { inmuebles } \\
\text { protegidos }\end{array}$ & $\begin{array}{l}\text { Total_ } \\
\text { equipamientos } \\
\text { uso público }\end{array}$ & & \\
\hline & & Frontones & $\begin{array}{l}\text { Total_fiestas } \\
\text { interés } \\
\text { turístico }\end{array}$ & & & \\
\hline & & Otros campos & $\begin{array}{l}\text { Total__ } \\
\text { bibliotecas } \\
\text { públicas }\end{array}$ & & & \\
\hline & & $\begin{array}{l}\text { Pabellones } \\
\text { polideportivos }\end{array}$ & Aforo_cines & & & \\
\hline & & $\begin{array}{l}\text { Piscinas aire } \\
\text { libre }\end{array}$ & $\begin{array}{l}\text { Aforo_ } \\
\text { recintos } \\
\text { escénicos y } \\
\text { musicales }\end{array}$ & & & \\
\hline & & $\begin{array}{l}\text { Piscinas } \\
\text { cubiertas }\end{array}$ & $\begin{array}{l}\text { Comercio } \\
\text { prendas de } \\
\text { vestir }\end{array}$ & & & \\
\hline & & $\begin{array}{l}\text { Pistas de } \\
\text { atletismo }\end{array}$ & $\begin{array}{l}\text { Comercio } \\
\text { calzado y } \\
\text { artículos de } \\
\text { cuero }\end{array}$ & & & \\
\hline & & Pistas de pádel & $\begin{array}{l}\text { Comercio } \\
\text { muebles, } \\
\text { iluminación } \\
\text { y otros art. de } \\
\text { hogar }\end{array}$ & & & \\
\hline & & $\begin{array}{l}\text { Pistas de } \\
\text { petanca }\end{array}$ & $\begin{array}{l}\text { Gestión de } \\
\text { salas de } \\
\text { espectáculos }\end{array}$ & & & \\
\hline & & $\begin{array}{l}\text { Pistas de } \\
\text { squash }\end{array}$ & $\begin{array}{l}\text { Salas de baile, } \\
\text { discotecas y } \\
\text { actividades } \\
\text { similares }\end{array}$ & & & \\
\hline
\end{tabular}




\begin{tabular}{|c|c|c|c|c|c|c|}
\hline \multicolumn{7}{|c|}{ ANÁLISIS FACTORIALES POR SEGMENTOS TURÍSTICOS TEÓRICOS } \\
\hline $\begin{array}{l}\text { sol y } \\
\text { playa }\end{array}$ & náutico & $\begin{array}{l}\text { Deporte- } \\
\text { Espacios } \\
\text { deportivos }\end{array}$ & cultural & naturaleza & $\begin{array}{l}\text { salud y } \\
\text { belleza }\end{array}$ & reuniones \\
\hline & & Pistas de tenis & $\begin{array}{l}\text { Otros } \\
\text { espectáculos }\end{array}$ & & & \\
\hline & & $\begin{array}{l}\text { Pistas } \\
\text { polideportivas }\end{array}$ & $\begin{array}{l}\text { Casinos } \\
\text { y salas de } \\
\text { juegos de azar }\end{array}$ & & & \\
\hline & & Salas & & & & \\
\hline & & $\begin{array}{l}\text { Otros espacios } \\
\text { convencionales }\end{array}$ & & & & \\
\hline & & Campos de golf & & & & \\
\hline & & Pistas de hípica & & & & \\
\hline & & $\begin{array}{l}\text { Circuitos de } \\
\text { karting }\end{array}$ & & & & \\
\hline & & Rocódromos & & & & \\
\hline & & Campos de tiro & & & & \\
\hline \multicolumn{7}{|c|}{ RESULTADOS DEL ANÁLISIS FACTORIAL } \\
\hline \multicolumn{7}{|c|}{ 1. IDONEIDAD } \\
\hline & 1.1. Matr & correlaciones & $\checkmark$ & $\checkmark$ & $\checkmark$ & $\checkmark$ \\
\hline & 1.2. Dete & $\begin{array}{r}\text { minante matriz } \\
\text { correlaciones }\end{array}$ & $\checkmark$ & $\checkmark$ & $\checkmark$ & $\checkmark$ \\
\hline & & 1.3. Bartlett & .00 & .00 & .00 & .00 \\
\hline & & 1.4. KMO & .50 & .50 & .938 & .738 \\
\hline & 1.5. Matr & anti - imagen & $\checkmark$ & $\checkmark$ & $\checkmark$ & $\checkmark$ \\
\hline \multicolumn{7}{|c|}{$\begin{array}{r}\text { 2. VARIANZA TOTAL } \\
\text { EXPLICADA }\end{array}$} \\
\hline & 2.1. Nún & ero de factores & 2 & 1 & 1 & 1 \\
\hline & $\%$ acumul & $\begin{array}{r}\text { do de varianza } \\
\text { explicada }\end{array}$ & 90,81 & 59,69 & 69,94 & 75,74 \\
\hline
\end{tabular}

Fuente: Elaboración propia, a partir de los resultados obtenidos con la utilización del paquete estadístico SPSS (v15).

En el segmento teórico de sol y playa, como era de suponer, las dos variables que lo conforman, esto es, presencia o no de litoral y número de playas con que cuenta el municipio, están altamente relacionadas y ambas conforman un único factor, el indicador de potencialidad turística al que se ha denominado IP_sol y playa. Algo parecido sucede con el segmento de recursos turísticos relacionado con las prácticas náuticas, pues el total de puertos deportivos y el número de estaciones náuticas por municipio presentan una correlación muy alta, agrupándose las dos en un mismo factor, el indicador de potencialidad IP_náutico. 
Respecto al segmento de los recursos deportivos, partiendo de la tipología de espacios deportivos recogida en el Inventario de Instalaciones Deportivas de Andalucía (Consejería de Turismo, Comercio y Deporte de la Junta de Andalucía), se obtuvieron dos factores. El primero agrupa los espacios deportivos relacionados con prácticas deportivas convencionales -según el Sistema de Información Multiterritorial de Andalucía (en adelante, SIMA)-, esto es, aquellos construidos para la práctica deportiva correspondiente a las tipologías más tradicionales. Disponen de referentes reglados con dimensiones establecidas aunque no en todos los casos se ajustan a las mismas y son espacios que cuentan con instalaciones como pistas, frontones, pabellones, campos, piscinas, salas, etc. El segundo factor aglutina a espacios construidos para la práctica deportiva y, aunque ésta pueda estar reglada, presentan unas dimensiones y características adaptadas a cada tipo. Son espacios más específicos (golf, pistas de hípica, etc.) y generalmente tienen unos requerimientos espaciales que hacen que su distribución sea desigual sobre el territorio.

Tabla 4

ESPACIOS DEPORTIVOS: MATRIZ DE COMPONENTES ROTADOS

\begin{tabular}{|c|c|c|}
\hline \multirow{2}{*}{ VARIABLES } & \multicolumn{2}{|c|}{ FACTORES } \\
\hline & $\begin{array}{c}\text { DEPORTES } \\
\text { CONVENCIONALES }\end{array}$ & $\begin{array}{l}\text { DEPORTES } \\
\text { SINGULARES }\end{array}$ \\
\hline Esp. dep. Espac. pequeños y no reglamentarios & 901 & .310 \\
\hline Esp. dep. Frontones &, 642 & 229 \\
\hline Esp. dep. Otros campos &, 875 &, 129 \\
\hline Esp. dep. Pabellones polideportivos &, 920 & 208 \\
\hline Esp. dep. Piscinas aire libre & 387 &, 732 \\
\hline Esp. dep. Piscinas cubiertas &, 759 &, 513 \\
\hline Esp. dep. Pistas de atletismo & ,706 & 294 \\
\hline Esp. dep. Pistas de padel &, 623 & 614 \\
\hline Esp. dep. Pistas de petanca & ,748 &, 180 \\
\hline Esp. dep. Pistas de squash & ,816 & 271 \\
\hline Esp. dep. Pistas de tenis &, 804 & 414 \\
\hline Esp. dep. Pistas polideportivas &, 934 & 294 \\
\hline Esp. dep. Salas &, 937 & 269 \\
\hline Esp. dep. Otros espacios convencionales &, 753 & 225 \\
\hline Esp. dep. Campos de golf & 080 &, 867 \\
\hline Esp. dep. Pistas de hípica & 190 &, 732 \\
\hline Esp. dep. Circuitos de karting & 099 &, 600 \\
\hline Esp. dep. Rocódromos &, 247 &, 430 \\
\hline Esp. dep. Otros espacios singulares & ,391 & ,771 \\
\hline
\end{tabular}

Método de extracción: Análisis de componentes principales. Método de rotación: Normalización Varimax con Kaiser. La rotación ha convergido en 3 iteraciones.

Fuente: Elaboración propia, a partir de los resultados obtenidos con la utilización del paquete estadístico SPSS (v15). 
Así pues, respecto a los espacios deportivos se puede concluir que las diecinueve variables originales pueden ser explicadas por la presencia de dos factores, a los que se denominará IP_deportes convencionales e IP_deportes singulares, que dan cuenta del 69,94\% de la varianza total, considerando que sólo el primer factor (referido a deportes convencionales) ya explica el 59,40\% de la varianza total.

Respecto a los espacios deportivos, al someter todas las variables al análisis factorial, éstas se han agrupado respetando la clasificación del SIMA, en espacios convencionales y singulares, excepto las piscinas al aire libre, que se han agrupado en el factor relativo a los espacios deportivos singulares, lo cual resulta muy interesante si se tiene en cuenta que, como se demuestra más adelante, este tipo de recursos deportivos está más ligado al turismo de costa que al turismo urbano.

Para el tratamiento de las variables relacionadas con el patrimonio cultural de los municipios, se ha realizado un único análisis factorial que agrupa las categorías teóricas «cultural histórico», «cultural artístico» y «cultural recreativo», con el fin de propiciar una reducción en el número de variables que facilite la interpretación de los resultados. Se han formado tres factores (Tabla 5), que explican el 75,68\% de la varianza total. El primero (IP_cultural) es el que más contribuye a explicar la varianza total (en un 30,64\%) y presenta una correlación muy alta con los recursos turísticos relacionados. El segundo factor (IP_ocio) lo componen las variables ligadas a las actividades recreativas o de ocio (gestión de salas de espectáculos, salas de baile, discotecas o casinos) y explica el 24,26\% de la varianza total. El tercer factor (IP_compras) está altamente correlacionado con los establecimientos de comercio al por menor de todo tipo de artículos (ver la última columna de la Tabla 4) y contribuye a explicar la varianza total en un 20,77\%.

\begin{tabular}{|c|c|c|c|}
\hline \multirow{2}{*}{ VARIABLES } & \multicolumn{3}{|c|}{ FACTORES } \\
\hline & CULTURA & OCIO & COMPRAS \\
\hline Total_museos & $\mathbf{8 4 0}$ &,- 025 & , 168 \\
\hline Total_bibliotecas públicas &, 858 &, 004 &,- 008 \\
\hline Aforo_cines & ,876 &, 074 &,- 008 \\
\hline Total_fiestas interés turístico &, 612 &,- 051 & 049 \\
\hline Total_bienes inmuebles protegidos &, 726 &,- 025 & 032 \\
\hline Aforo_recintos escénicos y musicales &, 779 & 071 & 092 \\
\hline Gestión de salas de espectáculos & 010 &, 973 &,- 004 \\
\hline Salas de baile, discotecas y actividades similares &,- 017 & 806 &,- 021 \\
\hline Otros espectáculos & 035 & , 845 & 003 \\
\hline Casinos y salas de juegos de azar &,- 006 & 900 &,- 016 \\
\hline Comercio prendas de vestir & 0,089 &,- 013 &, 992 \\
\hline Comercio calzado y artículos de cuero & 084 &,- 014 & 986 \\
\hline Comercio muebles, iluminación y otros art. de hogar &, 073 &,- 010 & ,982 \\
\hline
\end{tabular}

Método de extracción: Análisis de componentes principales. Método de rotación: Normalización Varimax con Kaiser. La rotación ha convergido en 4 iteraciones.

Fuente: Elaboración propia, a partir de los resultados obtenidos con la utilización del paquete estadístico SPSS (v15). 
Finalmente, respecto a los segmentos teóricos de salud y belleza y de reuniones, al estar representados cada uno por una única variable, se ha procedido a calcular, su puntuación tipificada (con media, 0 y desviación típica, 1), con el fin de homogeneizar sus valores con respecto a los de los indicadores de potencialidad calculados a través de análisis factoriales, pues, a partir de este momento, se trabajará con sus puntuaciones factoriales (con media, 0 y desviación típica, 1). Con las dos variables que componen el segmento teórico de naturaleza se ha procedido de igual manera, por resultar lo más aconsejable, vista su distribución.

Figura 2

PROCESO DE OBTENCIÓN DE LOS INDICADORES DE POTENCIALIDAD TURÍSTICA

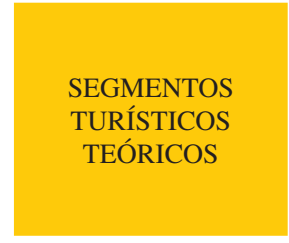

Sol y playa

Náutico

Deporte

Cultural histórico

Cultural artístico

Cultural recreativo

Naturaleza

Salud y Belleza

Reuniones
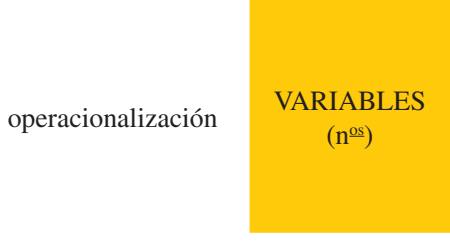

Análisis factoriales por grupos de recursos

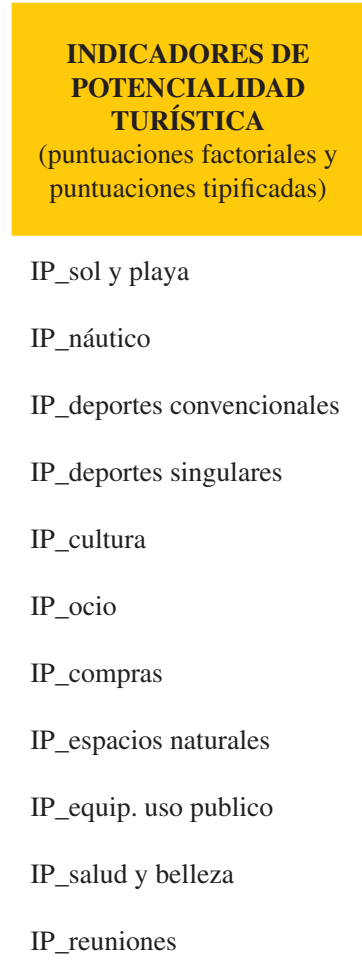

Fuente: Elaboración propia.

Como conclusión de esta parte del trabajo, se puede apuntar que, tras operacionalizar los segmentos de recursos turísticos teóricos a través de un amplio conjunto de variables, se les aplicaron a los mismos análisis factoriales por grupos de recursos para, con una mínima reducción en información, ganar en significación y capacidad de representación y obteniéndose así los once indicadores de potencialidad turística que servirán de punto de partida para la definición de una tipología de segmentos empíricos de recursos turísticos. 


\section{Análisis factoriales para los indicadores comunes de potencialidad turística}

En el apartado anterior se han tratado los recursos turísticos que, por su naturaleza, son específicos de los espacios en que se ubican, o dicho de otra manera, que forman parte del acervo natural o patrimonial de los territorios en los que se encuentran. Pero, también hay que considerar las instalaciones y equipamientos turísticos, comunes a todos o a varios de los segmentos de recursos turísticos definidos con anterioridad y cuyo desarrollo resulta fundamental para el turismo. Se trata, concretamente, del alojamiento, los establecimientos de restauración y las actividades de información turística, a los que se ha sumado el capital asociativo de los municipios. Según Junta de Andalucía (2008), a los conceptos de alojamiento $(23,6 \%)$ y restauración $(34,7 \%)$ fueron destinados la mayor parte del gasto diario de los visitantes de Andalucía y, en referencia a la información turística, su análisis resulta muy importante si se tiene en cuenta que, en 2007, cerca del $90 \%$ de los turistas nacionales organizaron su viaje a Andalucía de forma particular (sin intermediario), siendo este aspecto valorado por los usuarios con un 7 sobre 10 .

Así pues, siguiendo el proceso anterior, se ha tratado de operacionalizarlos en variables, agrupadas posteriormente en factores, pero, en este caso, serán utilizadas como variables de control, que permitirán comprobar la validez de los indicadores de potencialidad turística específicos. También se incluye en los análisis la variable «tamaño de población», para controlar el grado de dependencia de los distintos segmentos de recursos turísticos en relación con el número de habitantes de los municipios, pues, si bien resulta claro que recursos patrimoniales de carácter histórico, como los bienes inmuebles protegidos o los espacios naturales protegidos, no presentan una correlación elevada con el tamaño municipal, existen otros recursos, como el aforo de salas de cine, por poner un ejemplo, claramente relacionados con dicha variable.

Para incluir en este análisis la información sobre alojamiento y restauración se han tomado como variables los totales de plazas por tipo de establecimientos, disponibles en el SIMA, para 2006 en el primer caso y para 2003 en el segundo. Los datos sobre el número de oficinas de turismo y las webs turísticas del municipio proceden de bases de datos disponibles en la Consejería de Turismo, Comercio y Deporte de la Junta de Andalucía, y la información acerca de las asociaciones proviene del Registro de Asociaciones de Andalucía, gestionado por la Consejería de Justicia y Administración Pública de la Junta de Andalucía. La Tabla 6 muestra las variables que recogen información sobre cada uno de los segmentos de recursos turísticos comunes, así como los principales resultados de los análisis factoriales llevados a cabo.

Para analizar los datos relativos al alojamiento, si bien es verdad que en el SIMA se encuentra disponible la información clasificada por categorías del establecimiento, además de por tipo de alojamiento, se ha optado por utilizar únicamente esta última clasificación, para simplificar los datos. Así, llevado a cabo el análisis factorial, las cinco variables se resumen en dos factores, (Tabla 7). El primero de ellos, que explica el 51,23\% de la varianza total, coincide con los tipos de alojamiento más comunes en los núcleos urbanos y de costa. Es por ello que a este factor se le ha denominado IP_alojamiento urbano y de costa. El segundo factor, que captura el $21,22 \%$ de la varianza total, coincide con los establecimientos más relacionados con el alojamiento en zonas rurales y de naturaleza, por lo que se denominará IP_alojamiento rural. 
Tabla 6

INDICADORES DE POTENCIALIDAD TURISTIICA COMUNES

\begin{tabular}{|c|c|c|c|c|c|}
\hline \multicolumn{6}{|c|}{ ANÁLISIS FACTORIALES POR GRUPOS DE RECURSOS COMUNES } \\
\hline Alojamiento & \multicolumn{2}{|c|}{ Hostelería } & información turística & \multicolumn{2}{|c|}{ asociaciones } \\
\hline Plazas_hoteles & \multicolumn{2}{|c|}{$\begin{array}{l}\text { Plazas_Restaurantes } \\
\text { de } 5 \text { tenedores }\end{array}$} & $\begin{array}{l}\text { Total de oficinas de } \\
\text { turismo del municipio }\end{array}$ & \multicolumn{2}{|c|}{$\begin{array}{l}\text { Asociaciones: Cultura, } \\
\text { Ciencias, Artes y Letras }\end{array}$} \\
\hline $\begin{array}{l}\text { Plazas_hoteles/ } \\
\text { apartamentos }\end{array}$ & \multicolumn{2}{|c|}{$\begin{array}{l}\text { Plazas_Restaurantes } \\
\text { de } 4 \text { tenedores }\end{array}$} & $\begin{array}{l}\text { Total de webs } \\
\text { turísticas del } \\
\text { municipio }\end{array}$ & \multicolumn{2}{|c|}{$\begin{array}{l}\text { Asociaciones: } \\
\text { Deportivas }\end{array}$} \\
\hline $\begin{array}{l}\text { Plazas_apartamentos } \\
\text { turísticos }\end{array}$ & \multicolumn{2}{|c|}{$\begin{array}{l}\text { Plazas_Restaurantes } \\
\text { de } 3 \text { tenedores }\end{array}$} & & \multicolumn{2}{|c|}{$\begin{array}{l}\text { Asociaciones: } \\
\text { Económicas }\end{array}$} \\
\hline Plazas_campamentos & \multicolumn{2}{|c|}{$\begin{array}{l}\text { Plazas_Restaurantes } \\
\text { de } 2 \text { tenedores }\end{array}$} & & \multicolumn{2}{|c|}{$\begin{array}{l}\text { Asociaciones: } \\
\text { Históricas y } \\
\text { Costumbristas }\end{array}$} \\
\hline \multirow[t]{4}{*}{$\begin{array}{l}\text { Plazas_establecimientos } \\
\text { turísticos rurales }\end{array}$} & \multicolumn{2}{|c|}{$\begin{array}{l}\text { Plazas_Restaurantes } \\
\text { de } 1 \text { tenedores }\end{array}$} & & \multicolumn{2}{|c|}{$\begin{array}{l}\text { Asociaciones: Medios } \\
\text { de Comunicación y } \\
\text { Espectáculos }\end{array}$} \\
\hline & \multicolumn{2}{|c|}{$\begin{array}{l}\text { Plazas_Cafeterías de } \\
3 \text { tazas }\end{array}$} & & \multicolumn{2}{|c|}{$\begin{array}{l}\text { Asociaciones: } \\
\text { Musicales }\end{array}$} \\
\hline & \multicolumn{2}{|c|}{$\begin{array}{l}\text { Plazas_Cafeterías de } \\
2 \text { tazas }\end{array}$} & & \multicolumn{2}{|c|}{$\begin{array}{l}\text { Asociaciones: } \\
\text { Recreativas }\end{array}$} \\
\hline & \multicolumn{2}{|c|}{$\begin{array}{l}\text { Plazas_Cafeterías de } \\
1 \text { taza }\end{array}$} & & & \\
\hline \multicolumn{6}{|c|}{ RESULTADOS DEL ANÁLISIS FACTORIAL } \\
\hline \multicolumn{6}{|c|}{ 1. IDONEIDAD } \\
\hline \multicolumn{2}{|c|}{ 1.1. Matriz correlaciones } & $\checkmark$ & $\checkmark$ & $\checkmark$ & $\checkmark$ \\
\hline \multicolumn{2}{|c|}{ 1.2. Determinante matriz correlaciones } & $\checkmark$ & $\checkmark$ & $\checkmark$ & $\checkmark$ \\
\hline \multicolumn{2}{|c|}{ 1.3. Bartlett } & .00 & .00 & .00 & .00 \\
\hline \multicolumn{2}{|c|}{ 1.4. KMO } & .757 & .844 & .500 & .899 \\
\hline \multicolumn{2}{|c|}{ 1.5. Matriz anti - imagen } & $\checkmark$ & $\checkmark$ & $\checkmark$ & $\checkmark$ \\
\hline \multicolumn{6}{|c|}{ 2. VARIANZA TOTAL EXPLICADA } \\
\hline \multicolumn{2}{|c|}{ 2.1. Número de factores } & 2 & 1 & 1 & 1 \\
\hline 2.2. \% acumulado de var & ianza explicada & 72,45 & 62,48 & 73,73 & 86,66 \\
\hline
\end{tabular}

Fuente: Elaboración propia, a partir de los resultados obtenidos con la utilización del paquete estadístico SPSS (v15).

Respecto a los establecimientos de restauración, se han tenido en cuenta tanto restaurantes como cafeterías, clasificados en ambos casos por categorías. Pero, aplicado el análisis factorial y dada su alta correlación, se han agrupado todos en un único factor, denominado IP_restauración. Por otra parte, se han incluido las páginas webs que los municipios ponen a disposición de los turistas con información de utilidad para la planificación del viaje, así como las oficinas de turismo, que ofrecen información turística en destino. Al incluir ambas variables en un análisis factorial, y por tener alto nivel de correlación, forman un único factor, IP_información turística. 


\begin{tabular}{|l|c|c|}
\hline \multirow{2}{*}{ VARIABLES } & \multicolumn{2}{|c|}{ FACTORES } \\
\cline { 2 - 3 } & $\begin{array}{c}\text { ALOJAMIENTO URBANO } \\
\text { Y DE COSTA }\end{array}$ & $\begin{array}{c}\text { ALOJAMIENTO } \\
\text { RURAL }\end{array}$ \\
\hline $\begin{array}{l}\text { Total de plazas en establecimientos } \\
\text { turísticos rurales }\end{array}$ &,- 100 & $\mathbf{9 1 6}$ \\
\hline Plazas en campamentos &, 466 &, $\mathbf{5 0 5}$ \\
\hline Total de plazas en apartamentos turísticos & $\mathbf{8 5 7}$ &,- 012 \\
\hline Total de plazas en hoteles/apartamentos & $\mathbf{8 7 5}$ &, 091 \\
\hline Total de plazas en hoteles & $\mathbf{8 8 9}$ &, 046 \\
\hline
\end{tabular}

Método de extracción: Análisis de componentes principales. Método de rotación: Normalización Varimax con Kaiser. La rotación ha convergido en 3 iteraciones.

Fuente: Elaboración propia, a partir de los resultados obtenidos con la utilización del paquete estadístico SPSS (v15).

Para terminar con el grupo de indicadores de potencialidad turística comunes, también se ha considerado oportuno incluir el capital asociativo del municipio, en lo que a materia turística se refiere. Para ello, se han seleccionado las asociaciones relacionadas con la actividad turística, concretamente, las asociaciones de cultura, ciencias, artes y letras, deportivas, económicas, históricas y costumbristas, de medios de comunicación y espectáculos, musicales y las recreativas. En este caso, aplicado el análisis factorial, todas las variables se incluyen en un mismo factor, al que se ha denominado IP_asociaciones, que explica el 86,66\% de la varianza total.

\section{Identificación de tipologías de recursos turísticos}

Reducido el número inicial de variables que hacían referencia a los recursos turísticos específicos y extraídos los once factores o indicadores de potencialidad, que resumían las cuarenta y dos variables, se ha procedido a aplicar nuevamente la técnica de análisis factorial, esta vez sobre diez de los once indicadores de potencialidad ${ }^{3}$, con la finalidad de resumir la información contenida en los mismos en una serie de factores latentes, hasta ahora desconocidos, que permitan definir las tipologías de recursos turísticos. Es conveniente recordar que se va a operar con la puntuación factorial de los indicadores de potencialidad turística específicos, calculada con anterioridad, para eliminar los efectos negativos de la utilización de distintas unidades de medida para las diferentes variables.

Antes de analizar los resultados del análisis factorial, conviene describir someramente las pruebas realizadas para comprobar la idoneidad de dicha técnica, las cuales, como se verá más adelante, ponen de manifiesto la correlación existente entre las variables y la pertinencia de la utilización del análisis multivariante. Tanto el contenido de la matriz de correlaciones, como el valor de su determinante, los resultados del test de esfericidad de Bartlett y el valor

3 El factor IP_sol y playa ha sido eliminado de este nuevo proceso de extracción de factores a fin de evitar que su elevada correlación con las variables referentes a los recursos turísticos distorsionara los resultados. 
del índice de Kaiser-Meyer-Olkin (KMO) reflejan la existencia de correlaciones significativas entre las variables objeto de estudio, esto es, los indicadores específicos de potencialidad turística, y por tanto, la aptitud de la aplicación del análisis factorial para la detección de los factores subyacentes.

La Tabla 8 muestra los autovalores iniciales, así como las proporciones de la varianza explicada por cada factor y la varianza total explicada. Utilizando el análisis de componentes principales como método de extracción de los factores, el número óptimo de factores a extraer es de tres, (explican cerca de un $60 \%$ de la varianza total). Es decir, la información contenida en los diez indicadores de potencialidad turística puede ser explicada por la presencia de tres factores, a los cuales se ha decidido denominar tipologías de recursos turísticos, que explican un 59,93\% de la varianza total, siendo más de la mitad $(32,036 \%)$ explicada por el primer factor, y el resto capturada, más o menos en la misma medida, por el segundo y tercer factor.

Tabla 8

VARIANZA TOTAL EXPLICADA POR CADA FACTOR

\begin{tabular}{|c|c|c|c|c|c|c|c|c|c|}
\hline \multirow{2}{*}{ Componente } & \multicolumn{3}{|c|}{ Autovalores iniciales } & \multicolumn{3}{|c|}{$\begin{array}{l}\text { Sumas de las saturaciones } \\
\text { al cuadrado de la extracción }\end{array}$} & \multicolumn{3}{|c|}{$\begin{array}{l}\text { Suma de las saturaciones } \\
\text { al cuadrado de la rotación }\end{array}$} \\
\hline & Total & $\begin{array}{l}\% \text { de la } \\
\text { varianza }\end{array}$ & $\begin{array}{c}\% \\
\text { acumulado }\end{array}$ & Total & $\begin{array}{c}\% \text { de la } \\
\text { varianza }\end{array}$ & $\begin{array}{c}\% \\
\text { acumulado }\end{array}$ & Total & $\begin{array}{l}\% \text { de la } \\
\text { varianza }\end{array}$ & $\begin{array}{c}\% \\
\text { acumulado }\end{array}$ \\
\hline 1 & 3,204 & 32,036 & 32,036 & 3,204 & 32,036 & 32,036 & 2,544 & 25,438 & 25,438 \\
\hline 2 & 1,430 & 14,301 & 46,337 & 1,430 & 14,301 & 46,337 & 2,009 & 20,092 & 45,530 \\
\hline 3 & 1,359 & 13,595 & 59,932 & 1,359 & 13,595 & 59,932 & 1,440 & 14,402 & 59,932 \\
\hline 4 & ,984 & 9,844 & 69,776 & & & & & & \\
\hline 5 & ,982 & 9,818 & 79,594 & & & & & & \\
\hline 6 & 658 & 6,579 & 86,173 & & & & & & \\
\hline 7 & ,549 & 5,488 & 91,661 & & & & & & \\
\hline 8 & ,411 & 4,109 & 95,770 & & & & & & \\
\hline 9 &, 341 & 3,407 & 99,177 & & & & & & \\
\hline 10 & ,082 &, 823 & 100,000 & & & & & & \\
\hline
\end{tabular}

Método de extracción: Análisis de Componentes principales.

Fuente: Elaboración propia, a partir de los resultados obtenidos con la utilización del paquete estadístico SPSS (v15).

Seguidamente, para facilitar la interpretación de los resultados, se procedió a la rotación de los factores por el método Varimax, que minimiza el número de variables con saturaciones altas en cada factor (Tabla 9). La matriz de componentes rotados refleja las correlaciones parciales entre cada una de las variables objeto de agrupamiento y los nuevos factores que se han formado. Cuanto mayores sean dichas correlaciones, mejor representada estará la variable en el eje. 
Tabla 9

MATRIZ DE COMPONENTES ROTADOS

\begin{tabular}{|c|c|c|c|}
\hline \multirow{2}{*}{ VARIABLES } & \multicolumn{3}{|c|}{ FACTORES } \\
\hline & ST_URBANO & ST_COSTA & ST_NATURALEZA \\
\hline IP_deportes convencionales & ,944 & ,004 &, 014 \\
\hline IP_deportes singulares &, 010 & ,845 &, 023 \\
\hline IP_náutico &, 261 & ,694 &, 075 \\
\hline IP_cultura & ,912 & ,234 &, 061 \\
\hline IP_compras & ,260 &,- 017 &,- 006 \\
\hline IP_ocio &,- 059 & ,215 &,- 107 \\
\hline IP_espacios naturales &, 117 & ,107 & ,838 \\
\hline $\begin{array}{l}\text { IP_equipamientos de uso público(espacios } \\
\text { naturales) }\end{array}$ &,- 111 &,- 112 &, 843 \\
\hline IP_salud y belleza &, 305 & ,778 & 083 \\
\hline IP_reuniones & ,749 & ,288 &, 011 \\
\hline
\end{tabular}

Método de extracción: Análisis de componentes principales. Método de rotación: Normalización Varimax con Kaiser. La rotación ha convergido en 5 iteraciones.

Fuente: Elaboración propia, a partir de los resultados obtenidos con la utilización del paquete estadístico SPSS (v15).

El primer factor (que explica el 32,036\% de la varianza total), está altamente correlacionado con los indicadores de potencialidad ligados a los recursos turísticos característicos de los núcleos urbanos: práctica de los deportes que denominamos convencionales; actividades de carácter cultural; actividades relacionadas con turismo de reuniones y, en menor medida, turismo de compras (que, aunque presenta una saturación no demasiado alta sobre el primer factor, es la más alta y positiva, siendo la correlación con los otros factores muy baja y negativa). Este factor se denomina Tipología de recursos turísticos_URBANO (en adelante, ST_URBANO).

El segundo factor explica el 14,301\% de la varianza total y presenta una correlación elevada con la práctica de los deportes singulares; las actividades en balnearios y spas; el desarrollo de prácticas náuticas en puertos deportivos y, por último y en menor medida, las actividades recreativas y de ocio. Se ha denominado Tipología de recursos turísticos_COSTA (en adelante, ST_COSTA) por encontrarse estos recursos ligados fundamentalmente a las zonas de litoral.

Con una capacidad explicativa de la varianza total del 13,595\% están los indicadores de potencialidad altamente correlacionados con las actividades ligadas al entorno natural: 
espacios naturales protegidos y sus equipamientos de uso público. Este tercer factor se ha denominado Tipología de recursos turísticos_NATURALEZA (en adelante ST_NATURALEZA).

La Figura 3 recoge la representación de cada uno de los indicadores de potencialidad en los nuevos factores creados, de forma que cada grupo de indicadores de potencialidad turística se sitúa en torno al eje que representa su tipología de recursos turísticos.

Figura 3

TIPOLOGÍAS DE RECURSOS TURÍSTICOS IDENTIFICADAS

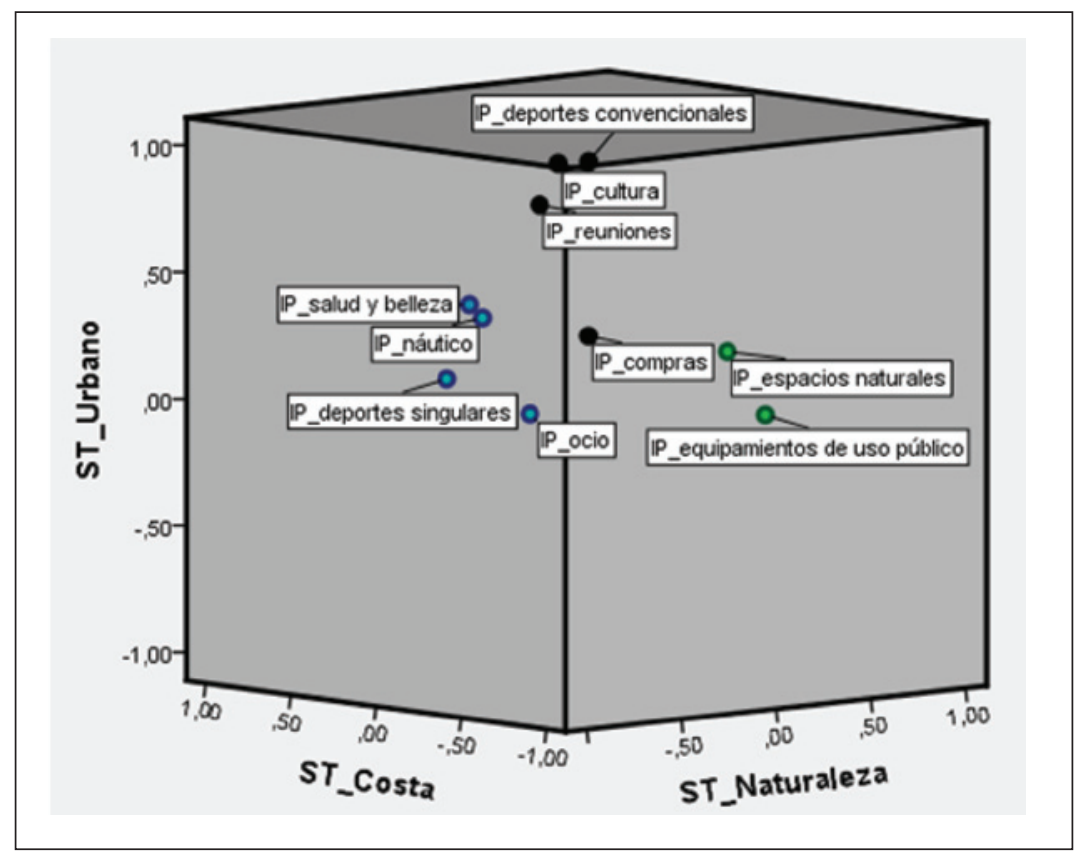

Fuente: Elaboración propia.

En definitiva, los diez indicadores de potencialidad definidos en el paso anterior pueden ser resumidos en tres factores o tipologías de recursos turísticos, que se corresponden en gran medida con los patrones de oferta turística que ofrecen las zonas urbanas, costeras y rurales, respectivamente (Figura 4). Así, sobre el eje denominado ST_URBANO, se agrupan los indicadores de potencialidad turística relacionados con el turismo de compras, el de reuniones, el turismo cultural y el de deportes convencionales. En el eje ST_NATURALEZA quedan recogidos los indicadores de potencialidad turística que hacen referencia a los espacios naturales, así como a los equipamientos de uso público de dichos espacios. Por último, sobre el eje denominado ST_COSTA se incluyen los indicadores asociados a las prácticas náuticas, a los deportes singulares (piscinas, golf, hípica, etc.), al turismo de salud y belleza y al turismo de ocio. 
Figura 4

PROCESO DE OBTENCIÓN DE LOS SEGMENTOS DE RECURSOS TURÍSTICOS

\begin{tabular}{|c|c|c|c|c|c|c|}
\hline $\begin{array}{c}\text { SEGMENTOS } \\
\text { TURÍSTICOS } \\
\text { TEÓRICOS }\end{array}$ & $\begin{array}{l}\text { Operacionali- } \\
\text { zación }\end{array}$ & $\begin{array}{l}\text { VARIABLES } \\
\left(\mathrm{n}^{\mathrm{os}}\right)\end{array}$ & $\begin{array}{l}\text { Análisis } \\
\text { factorial } \\
\text { por tipo } \\
\text { de recurso } \\
\text { turístico }\end{array}$ & $\begin{array}{l}\text { INDICADORES } \\
\text { POTENCIALIDAD } \\
\text { TURÍSTICA } \\
\text { (puntuaciones } \\
\text { factoriales) }\end{array}$ & $\begin{array}{l}\text { Análisis } \\
\text { factorial }\end{array}$ & $\begin{array}{c}\text { SEGMENTOS } \\
\text { DE RECURSOS } \\
\text { TURISTICOS } \\
\text { (puntuaciones } \\
\text { factoriales) }\end{array}$ \\
\hline Sol y playa & & & & $\begin{array}{l}\text { IP_deportes } \\
\text { convencionales }\end{array}$ & & \\
\hline Náutico & & & & IP_cultura & & ST_URBANO \\
\hline Deporte & & & & IP_reuniones & & \\
\hline Cultural histórico & & & & IP_compras & & \\
\hline Cultural artístico & & & & $\begin{array}{l}\text { IP_deportes } \\
\text { singulares }\end{array}$ & & \\
\hline Cultural Recreativo & & & & IP_náutico & & ST COSTA \\
\hline Naturaleza & & & & IP_salud y belleza & & \\
\hline Salud y Belleza & & & & IP_ocio & & \\
\hline Reuniones & & & & $\begin{array}{l}\text { IP_espacios naturales } \\
\text { IP_equip. uso publico }\end{array}$ & & ST_NATURALEZA \\
\hline
\end{tabular}

Fuente: Elaboración propia.

\section{Validación de las tipologías de recursos turísticos}

Definidos los tres factores que resumen los tipos de recursos turísticos (urbano, costa y rural) de los municipios andaluces, hay que proceder a su validación. Para ello, se han utilizado las variables que hacían referencia a los indicadores de potencialidad de los recursos turísticos comunes de las tres tipologías definidas: IP_alojamiento urbano, IP_alojamiento rural, IP_restauración, IP_información turística e IP_asociaciones. Estos indicadores serán utilizados como variables de control, junto con la variable IP_sol y playa, que hace referencia a la presencia o no de zona costera en el municipio. Aunque ésta fue eliminada del proceso de extracción de factores, para evitar que su elevada correlación con las variables referentes a los recursos turísticos distorsionara los resultados, se ha creído conveniente incluirla en esta parte del análisis. También se ha utilizado como variable de control el tamaño poblacional de los municipios. Los resultados se exponen en la Tabla 10.

El tamaño de población está fuertemente correlacionado con la tipología de recursos turísticos urbanos. Si bien, algunas de las variables recogidas en este factor, como los bienes inmuebles protegidos o las fiestas de interés turístico, presentan una correlación muy baja con esta variable, por tratarse de parte del patrimonio histórico del territorio, con independencia del número de habitantes del mismo, otras variables del mismo factor, como son el número de espacios deportivos convencionales, de recintos escénicos y musicales, de museos, de cines o de bibliotecas, están altamente correlacionados con el tamaño poblacional ${ }^{4}$. No ocurre lo

4 Para realizar estas comprobaciones, se han calculado las correlaciones bivariadas entre las cuarenta y dos variables originales (a partir de las cuales se obtienen los once indicadores de potencialidad turística específicos, los cinco indicadores de potencialidad turística comunes y las tres tipologías de recursos turísticos) y el tamaño de población, aunque, por brevedad, no han sido incluidas. 
mismo con los segmentos de costa y rural, pues, aunque el primero presenta una correlación positiva y significativa $(0,239)$, ésta es muy baja, lo cual resulta lógico si se tiene en cuenta que la implementación de recursos turísticos en las zonas costeras se realiza, no tanto en función del número de habitantes, cuanto de la afluencia de visitantes. Algo parecido ocurre con el segmento rural, cuya correlación con el tamaño de población ni siquiera es significativa. La variable que hace referencia a la presencia de zona costera en el municipio presenta una alta correlación con la tipología de recursos turísticos de costa.

Un comportamiento similar se observa en los indicadores de potencialidad turística de alojamiento urbano y de costa, por un lado, y de alojamiento de naturaleza, por otro. El primero está altamente correlacionado la tipología turística de costa $(0,738)$ y, en menor medida, aunque también de forma positiva, con la tipología urbana. Por su parte, el indicador de potencialidad de turismo rural presenta una correlación significativa y de signo positivo con la tipología turística ligada a la naturaleza. La variable referida a los establecimientos de restauración está fuertemente correlacionada con la tipología turística urbana $(0,737 \%)$ y también de manera positiva, aunque en una proporción algo menor, con la tipología de costa. Sin embargo, no existe correlación significativa entre el indicador de potencialidad turística de restauración y la tipología turística rural. La información turística tiene una correlación significativa y positiva con las tres tipologías de recursos turísticos, aunque, para la tipología urbana, esta correlación es muy elevada, mientras que para la tipología de costa es bastante menor y para la de naturaleza es prácticamente inexistente.

Tabla 10

CORRELACIONES BIVARIADAS ENTRE TIPOLOGÍAS DE RECURSOS TURÍSTICOS Y VARIABLES DE CONTROL

\begin{tabular}{|c|c|c|c|c|c|c|c|c|}
\hline $\begin{array}{r}\text { VARIABI } \\
\text { CONT }\end{array}$ & $\begin{array}{l}\text { ES DE } \\
\text { ROL }\end{array}$ & $\begin{array}{c}\text { Población } \\
\text { total } \\
\text { (Padrón 06) }\end{array}$ & Litoral & $\begin{array}{c}\mathrm{IP}_{-} \\
\text {alojamiento } \\
\text { urbano y }\end{array}$ & $\begin{array}{l}\mathrm{IP}_{-} \\
\text {alojamiento } \\
\text { rural }\end{array}$ & $\begin{array}{l}\mathrm{IP}_{-} \\
\text {restauración }\end{array}$ & $\begin{array}{l}\mathrm{IP}_{-} \\
\text {información } \\
\text { turística }\end{array}$ & $\begin{array}{c}\mathrm{IP}_{-} \\
\text {asociaciones }\end{array}$ \\
\hline & $\begin{array}{l}\text { Correlación } \\
\text { de Pearson }\end{array}$ &, $905(* *)$ &, $148(* *)$ &, $347(* *)$ & ,039 &, $737(* *)$ &, $689(* *)$ &, $905(* *)$ \\
\hline ST_URBANO & $\begin{array}{l}\text { Sig. } \\
\text { (bilateral) }\end{array}$ &, 000 &, 000 &, 000 &, 277 & ,000 &, 000 &, 000 \\
\hline & $\mathrm{N}$ & 769 & 769 & 761 & 761 & 769 & 769 & 769 \\
\hline & $\begin{array}{l}\text { Correlación } \\
\text { de Pearson }\end{array}$ &, $239(* *)$ &, $537(* *)$ &, $738(* *)$ & ,054 &, $532(* *)$ &, $272(* *)$ &, $180(* *)$ \\
\hline ST_COSTA & $\begin{array}{l}\text { Sig. } \\
\text { (bilateral) }\end{array}$ &, 000 &, 000 &, 000 & ,139 &, 000 &, 000 &, 000 \\
\hline & $\mathrm{N}$ & 769 & 769 & 761 & 761 & 769 & 769 & 769 \\
\hline & $\begin{array}{l}\text { Correlación } \\
\text { de Pearson }\end{array}$ &, 036 &, $078(*)$ & ,012 &, $252(* *)$ &, 040 &, $092(*)$ &, 030 \\
\hline ST_RURAL & $\begin{array}{l}\text { Sig. } \\
\text { (bilateral) }\end{array}$ & ,319 &, 031 & ,739 &, 000 &, 263 & 011 & ,400 \\
\hline & $\mathrm{N}$ & 769 & 769 & 761 & 761 & 769 & 769 & 769 \\
\hline
\end{tabular}

(**) Las correlación es significativa al nivel 0,01 (bilateral). (*) Las correlación es significativa al nivel 0,05 (bilateral) Fuente: Elaboración propia, a partir de los resultados obtenidos con la utilización del paquete estadístico SPSS (v15). 
Para terminar con las variables de control, se comprobó la correlación entre el capital asociativo relacionado con el turismo en el municipio y el tipo de recursos turísticos que predominan en el mismo, obteniéndose una relación positiva y muy elevada entre el indicador de potencialidad de asociaciones y la tipología turística urbana, lo cual debe responder a que cerca del 75\% de las mismas están incluidas en las categorías de culturales, históricas, deportivas y musicales, actividades recogidas en esta tipología. Sin embargo, la correlación con la tipología de costa, aunque significativa y positiva, es muy baja, y con la rural ni siquiera es significativa.

\section{CARACTERIZACIÓN DE LOS MUNICIPIOS TURÍSTICOS ANDALUCES. ANÁLISIS DE CON- GLOMERADOS}

Se ha aplicado la técnica multivariante conocida como análisis cluster $^{5}$ sobre las puntuaciones factoriales de las tres tipologías de recursos turísticos (urbana, de costa y rural) identificadas en el apartado anterior para realizar una clasificación de los 770 municipios andaluces en agrupaciones naturales, según su comportamiento con respecto a los segmentos de recursos turísticos.

A diferencia de otras técnicas multivariantes basadas en criterios de dependencia e independencia entre las variables, el análisis cluster confiere a todas las variables la misma función en la configuración de los grupos. No tiene como finalidad la explicación en términos estadísticos de un fenómeno, sino clasificar una población, definida por unas características determinadas, en un reducido número de grupos mutuamente exclusivos y exhaustivos (Sánchez Cuenca, 1990).

Se ha mencionado con anterioridad que se trabajará con las puntuaciones factoriales de las variables que van a servir como clasificadoras, esto es, las llamadas tipologías de recursos turísticos. Se insiste en esta idea porque, para aplicar esta técnica analítica, es fundamental la existencia de un número reducido de variables, la igualdad de medida y la existencia de incorrelación entre ellas. Los datos utilizados cumplen todos estos requisitos, pues se trabajará con sólo tres variables, con unidades de medida estandarizadas (puntuaciones factoriales) y con correlación entre los factores nula, por ser éstos ortogonales.

\section{Descripción de los conglomerados: identificación de la estructura turística municipal de Andalucía}

Se ha optado por comenzar ejecutando un método jerárquico para definir el número inicial de conglomerados, a partir del cual, por prueba y error, tratar de fijar los clusters definitivos $^{6}$. De entre todas las posibilidades que se probaron, se optó por seleccionar la que

5 La técnica de análisis cluster se suele utilizar como complementaria del análisis factorial, pues ayuda a explicar las razones de la formación de determinados factores que actúan como separadores de unos grupos respecto a otros, poniendo en evidencia las características que los diferencian.

6 Para ello, aplicando el método de vinculación de Ward, se obtuvo una solución inicial de 3 conglomerados, que fue el número dado al aplicar el procedimiento de agrupación no jerárquico de K-medias. Esta solución no resultó acertada, pues dividía los municipios en tres grupos (de 23, 25 y 533 municipios), concentrando demasiados casos en el último conglomerado. 
formaba seis clusters, que presentan un tamaño mínimo de 1 municipio y máximo de 526. A priori, un análisis de este tipo, del que resulta un conglomerado con un único individuo (o municipio, en este caso), no debería ser aceptado como solución válida, pero se han hecho pruebas con 4, 5, 6, 8, 9 y 10 conglomerados, y los resultados que arrojaban no resultaban fácilmente interpretables.

Respecto a las distancias entre los centros de cada cluster, éstas indican el grado de diferenciación entre ellos, por lo que, según los resultados que recoge la Tabla 11, se puede afirmar que los grupos 3 y 4 , así como el 2 y 3, son los que presentan mayores diferencias entre ellos.

DISTANCIAS ENTRE LOS CENTROS DE LOS CONGLOMERADOS FINALES

\begin{tabular}{|c|c|c|c|c|c|c|}
\hline CONGLOMERADO & $\mathbf{1}$ & $\mathbf{2}$ & $\mathbf{3}$ & $\mathbf{4}$ & $\mathbf{5}$ & $\mathbf{6}$ \\
\hline $\mathbf{1}$ & & 5,703 & 8,095 & 13,013 & 6,263 & 5,591 \\
$\mathbf{2}$ & 5,703 & & $\mathbf{1 3 , 7 2 2}$ & 11,884 & 3,956 & 1,948 \\
$\mathbf{3}$ & 8,095 & $\mathbf{1 3 , 7 2 2}$ & & $\mathbf{1 7 , 2 0 8}$ & 13,261 & 13,598 \\
$\mathbf{4}$ & 13,013 & 11,884 & $\mathbf{1 7 , 2 0 8}$ & & 8,023 & 11,785 \\
$\mathbf{5}$ & 6,263 & 3,956 & 13,261 & 8,023 & & 3,985 \\
$\mathbf{6}$ & 5,591 & 1,948 & 13,598 & 11,785 & 3,985 & \\
\hline
\end{tabular}

Fuente: Elaboración propia, a partir de los resultados obtenidos con el paquete estadístico SPSS (v15).

Llegados a este punto, es imprescindible la descripción y caracterización de los grupos obtenidos en la clasificación, cuya distribución queda recogida en la Tabla 12.

Tabla 12

NÚMERO DE CASOS EN CADA CONGLOMERADO

\begin{tabular}{|c|c|c|}
\hline Conglomerado & Casos & \% respecto al total \\
\hline 1 & 15 & $1,95 \%$ \\
\hline 2 & 217 & $28,18 \%$ \\
\hline 3 & 1 & $0,13 \%$ \\
\hline 4 & 4 & $0,52 \%$ \\
\hline 5 & 6 & $0,78 \%$ \\
\hline 6 & 527 & $68,44 \%$ \\
\hline Total & $\mathbf{7 7 0}$ & $\mathbf{1 0 0}$ \\
\hline
\end{tabular}

Fuente: Elaboración propia, a partir de los resultados obtenidos con el paquete estadístico SPSS (v15).

El conglomerado 1, con 15 casos y un peso sobre el total de cerca del $2 \%$, está compuesto por municipios de litoral con patrones de comportamiento respecto a la actividad turística muy similares: fuerte implementación de recursos turísticos, siendo esta parcela la principal fuente de desarrollo económico del territorio. El peso del factor ST_COSTA es muy elevado (Tabla 13), estando muy poco afectado tanto por el factor ST_NATURALEZA como por el ST_CULTURAL. 
El conglomerado 2 está compuesto por 217 casos, algo más del 28\% del total. Observando la distancia media de sus componentes al centro del mismo, para los tres factores, se ve que es el factor naturaleza el que presenta un mayor peso, aún cuando éste es bastante bajo. En general, se trata de municipios de menos de 10.000 habitantes, sin litoral y a cuyo término municipal pertenece, al menos, un espacio natural protegido, aunque más de la mitad de ellos están afectados por dos o más espacios de este tipo. Sin embargo, cerca del $90 \%$ de estos municipios no cuentan con museos, ni con fiestas de interés turístico, y más de un 30\% no poseen ningún bien inmueble protegido.

El conglomerado 3 está formado por un solo municipio, Marbella, con un patrón con respecto a la presencia de las tipologías de recursos turísticos muy similar al del conglomerado 1 (gran peso de los recursos relacionados con el turismo de costa y casi total ausencia de la componente cultural y de naturaleza, pero con peso bastante mayor de los recursos de litoral), por tratarse éste de un caso extremo, y sin comparación en Andalucía, de municipio turístico de costa.

El conglomerado 4 lo constituyen 4 casos (0,52\% sobre el total): Córdoba, Granada, Málaga y Sevilla. Se trata de las cuatro capitales andaluzas con mayor patrimonio histórico y cultural, tal y como refleja el peso del segmento de recursos turísticos ST_CULTURA en la tabla de distancias a los centros de los conglomerados finales (Tabla 13).

El conglomerado 5 está compuesto por 6 municipios (0,78\% del total) de más de 100.000 habitantes, a excepción de La Línea de la Concepción. Entre ellos están tres de las capitales de provincia de Andalucía, siendo el resto municipios con un peso importante en el desarrollo económico de la región. Respecto al peso de las tipologías de recursos turísticos, es el factor ST_CULTURA el que se da en mayor medida, pero con un valor medio bastante discreto. Las tipologías de costa y naturaleza, aunque con medias positivas, están escasamente representadas.

Por último, el conglomerado 6 es el más numeroso. Está formado por 527 municipios, de los cuales más del $80 \%$ son menores de 10.000 habitantes, sin litoral y sin presencia relevante de recursos turísticos de ningún tipo, ni culturales, ni de costa, ni de naturaleza.

Tabla 13

CENTROS DE LOS CONGLOMERADOS FINALES

\begin{tabular}{|l|c|c|c|c|c|c|}
\hline \multirow{2}{*}{\multicolumn{1}{|c|}{ FACTOR }} & \multicolumn{7}{|c|}{ CONGLOMERADO } \\
\cline { 2 - 7 } & $\mathbf{1}$ & $\mathbf{2}$ & $\mathbf{3}$ & $\mathbf{4}$ & $\mathbf{5}$ & $\mathbf{6}$ \\
\hline ST_CULTURA &,- 11686 &,- 12847 & 1,00228 & $\underline{\mathbf{1 1 , 6 8 8 5 3}}$ & $\underline{\mathbf{3 , 6 9 5 3 1}}$ &,- 07661 \\
ST_COSTA & $\underline{\mathbf{5 , 4 1 5 5 1}}$ &,- 18407 & $\underline{\mathbf{1 3 , 4 3 0 1 5}}$ &,- 05740 &, 45523 &,- 10879 \\
ST_NATURALEZA &, 28343 & $\underline{\mathbf{1 , 3 6 6 3 7}}$ &, 08028 &, 11086 &, 57746 &,- 57936 \\
\hline
\end{tabular}

Fuente: Elaboración propia, a partir de los resultados obtenidos con el paquete estadístico SPSS (v15).

Por otra parte, las similitudes estructurales existentes entre algunos de los clusters llevan a plantearse la posibilidad de reducir su número. Así, los clusters 1 y 3 reproducen el mismo 
modelo turístico, definido como «costa puro». Las pruebas de comparación de las medias realizadas corroboran que, con respecto a la tipología de recursos ST_COSTA, existen diferencias significativas entre los conglomerados 1 y 3 y el resto, por lo que se puede concluir que existe un tipo de municipios turísticos, formado por 16 casos y que denominaremos costa puro, con un peso aplastante de los recursos turísticos ligados a la presencia de litoral y escasa presencia del resto.

Los conglomerados 4 y 5 también son susceptibles de considerarse como un único grupo, al que podría denominarse urbano puro, pues presentan claras diferencias de medias con respecto al resto, fundamentalmente en lo que se refiere a la tipología de recursos turísticos culturales, de los que muestran una gran presencia. La carga de recursos ligados al turismo de naturaleza es muy baja, al igual que la de los recursos de costa, pues su patrón de desarrollo turístico está bastante más orientado al segmento turístico urbano y cultural que al de litoral.

El cluster 2, formado por 217 municipios, cuente con una mayor presencia de recursos de la tipología de naturaleza. En su totalidad, están afectados, al menos, por un espacio natural protegido (cerca del 50\% de los mismos están afectados por dos). Además, en la componente cultural, alrededor del $70 \%$ cuenta con, al menos, un bien cultural protegido, alzándose la media hasta cuatro bienes culturales protegidos por municipio. Se trata, en su mayoría, de municipios sin litoral $(93,1 \%)$, de los que 18 son ciudades medias de interior con relevancia turística, como Arcos de la Frontrera, Lucena, Moguer, Antequera o Ronda. Se ha denominado a este grupo urbano mixto.

El grupo más numeroso es el constituido por 527 municipios, en su mayoría de interior $(95,4 \%)$, casi sin recursos de turismo de naturaleza (el $83 \%$ no están afectados por ningún espacio natural protegido) y con escasa presencia de recursos turísticos culturales (algo más del $60 \%$ de los mismos cuentan con uno o ningún bien de interés cultural). Se le ha denominado como rural.

Así pues, se definen cuatro tipos de municipios en función de los recursos turísticos que poseen (Tabla 14): municipios «urbanos puros», «costa puros», «urbanos mixtos» y «rurales», representados en el Mapa 1, en que la leyenda de colores hace referencia a la tipología de municipio turístico y el tamaño de la marca está relacionado con el tamaño poblacional.

Tabla 14

TIPOLOGÍA DE MUNICIPIOS TURÍSTICOS EN ANDALUCÍA

\begin{tabular}{|l|c|c|c|}
\hline \multirow{2}{*}{$\begin{array}{c}\text { TIPOS DE MUNICIPIOS } \\
\text { TURÍSTICOS }\end{array}$} & \multicolumn{3}{|c|}{ TIPOS DE SEGMENTOS DE RECURSOS TURÍSTICOS } \\
\cline { 2 - 4 } & ST_CULTURA & ST_COSTA & ST_NATURALEZA \\
\hline URBANO PURO & +++ & + & + \\
\hline COSTA PURO & - & +++ & + \\
\hline URBANO MIXTO & + & + & ++ \\
\hline RURAL & - & - & - \\
\hline
\end{tabular}

Fuente: Elaboración propia. 


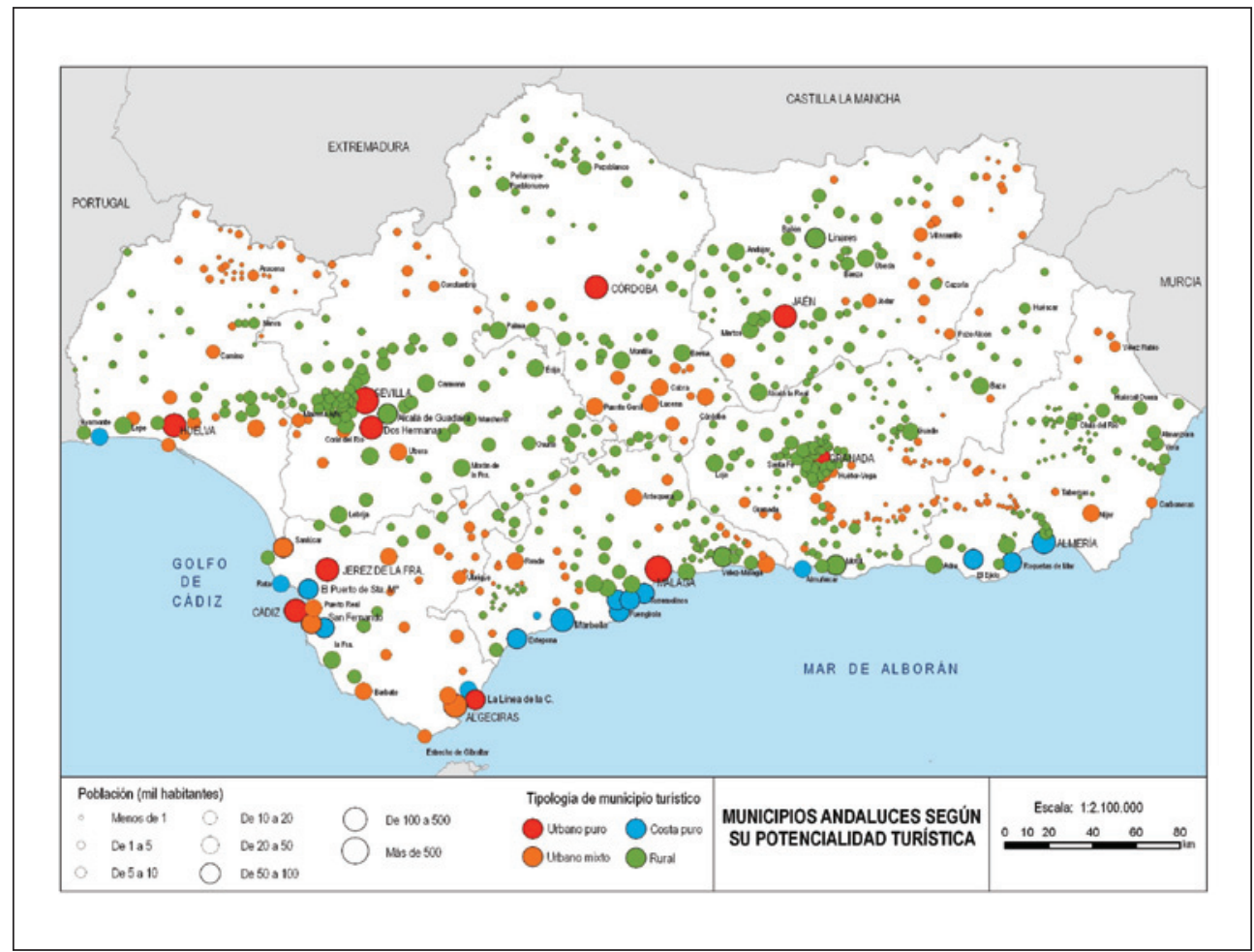

Fuente: Elaboración propia.

\section{Validación de los conglomerados}

Para la validación de los conglomerados obtenidos en el análisis anterior, se ha realizado un análisis de la varianza, con el fin de conocer las diferencias que introducen los factores (variables dependientes) en cada uno de los conglomerados obtenidos, o dicho de otra forma, a través de este análisis se podrá saber si cada uno de los factores permite localizar diferencias significativas entre cada uno de los conglomerados. De no ser así, habría que eliminar la variable en cuestión del proceso de formación de los clusters, o iniciar el proceso con un número distinto de éstos. La Tabla 15 recoge el análisis de la varianza aplicado a las tipologías turísticas con respecto a los seis grupos de municipios obtenidos. Según ésta, el nivel de significación de la F de Fisher indica que los tres factores utilizados producen diferencias significativas en la definición de los seis conglomerados y, por tanto, corrobora la pertinencia de utilización de todos ellos (ST_CULTURA, ST_COSTA y ST_ NATURALEZA) para la agrupación de los municipios según el tipo de recursos turísticos predominantes en cada uno de ellos (Mapa 1). 
Tabla 15

ANÁLISIS DE LA VARIANZA

\begin{tabular}{|l|c|c|}
\hline SEGMENTOS TURÍSTICOS & F de Fisher & Sig. \\
\hline ST_CULTURA & 737,256 &, 000 \\
\hline ST_COSTA & 729,367 &, 000 \\
\hline ST_NATURALEZA & 487,629 &, 000 \\
\hline
\end{tabular}

Fuente: Elaboración propia, a partir de los resultados obtenidos con el SPSS (v15).

\section{CONCLUSIONES}

El territorio adquiere una función singular en el nuevo modelo de desarrollo turístico, lo que obliga a observarlo y analizarlo desde una óptica más amplia y diversa. Para ello, es necesario impulsar nuevos modelos de análisis que tengan la capacidad de aprehender los elementos clave del mismo para que, sobre ellos, sea posible articular propuestas para su nueva funcionalidad que sirvan de base para articular estrategias de desarrollo turístico en las que lo local-territorial es el componente básico.

Esto es, precisamente, lo que permite la aplicación la metodología propuesta en este artículo, como modelo de análisis de la realidad del turismo de una determinada Comunidad Autónoma a escala municipal, identificando las características de la oferta que los municipios presentan sobre la base de sus componentes fundamentales, estableciendo para ello los diferentes ámbitos de intervención territorial que le son propios.

La aplicación del modelo analítico a la Comunidad Autónoma de Andalucía, especialmente compleja por el número y variedad de realidades municipales que agrupa, ha permitido contrastar la funcionalidad del mismo, identificando seis ámbitos territoriales diferenciados como caracterización del sistema turístico regional de Andalucía.

Esta distinción facilita una formulación ad hoc de la política turística andaluza, que podrá orientarse a fortalecer las capacidades y afrontar los déficit específicos de cada cluster, superando la etapa de la política turística generalista que termina generando una tremenda ineficiencia en la gestión de los cada vez más escasos recursos dedicados a la planificación y gestión del turismo por parte de la administración pública.

Los resultados obtenidos demuestran que la metodología propuesta es adecuada tanto para la identificación de las tipologías de recursos turísticos como para la posterior segmentación de los clusters que conforman un sistema turístico regional. Se trata, por tanto, de una metodología replicable para el análisis de cualquier territorio, que facilita enormemente la aplicación de políticas turísticas específicas, lo que supone un tremendo avance, especialmente en estos momentos, en los que la mayoría de los expertos coinciden que se está produciendo una segmentación creciente del mercado turístico que favorece la consolidación de los denominados turismos específicos. Éstos exigen un nivel de respuesta desde el lado de la oferta mucho más especializado, por lo que las políticas desarrolladas en respuesta a esta demanda también lo deben ser. 


\section{BIBLIOGRAFÍA}

AAS, C., LADKIN, A. y FLETCHER, J. (2005): «Stakeholder collaboration and heritage management», Annals of Tourism Research, 32 (1), 28-48.

AGUILÓ, E. (1998): «Política turística», en MELLA, J. M. (coord.): Economía y política regional en España ante la Europa del siglo XXI. Madrid, AKAL ediciones, 445-460.

ANTÓN, S., y DURO, J.A. (2010): «Innovación turística en España: retos de la política turística, gobernanza de los destinos y desarrollo de sistemas territoriales de innovación», Estudios Turísticos, 185, 7-32.

BARRADO, D. (2011): «Recursos territoriales y procesos geográficos: el ejemplo de los recursos turísticos», Estudios Geográficos, Vol. LXXII, 270, 35-58.

BARRADO, D. y ÁVILA, R. (2005): «Nuevas tendencias en el desarrollo de destinos turísticos: marcos conceptuales y operativos para su planificación y gestión», Cuadernos de Turismo, 15, 27-43.

BARRADO, D. y SÁEZ, A. (2008): «La dehesa: un espacio multifuncional para un aprovechamiento turístico diversificado», en VERA, J.F e IVARS, J.A. (Eds.): Espacios turísticos. Mercantilización, paisaje e identidad. Instituto Universitario de Investigaciones Turísticas. Universidad de Alicante. Alicante, 461-472.

BOTE, V. y MARCHENA, M. (1996): «Política turística», en PEDREÑO, A. (Dir.): Introducción a la economía del turismo en España. Madrid, Civitas, 295-326.

BRANWELL, B. y LANE, B. (1999): «Collaboration and Partnerships for Sustainable Tourism», Journal of Sustainable Tourism, 7, 179-181.

CEBRIÁN, F. (2008): «Turismo rural y desarrollo local: relaciones, desafíos, propuestas», en CEBRIÁN, F. (Coord.): Turismo rural y desarrollo local. Cuenca. Servicio de Publicaciones Universidad de Castilla-La Mancha; Secretariado de Publicaciones Universidad de Sevilla, 11-25.

CEBRIÁN, F. y GARCÍA, J.A. (2010): «Propuesta metodológica para la identificación, clasificación y puesta en valor de los recursos territoriales del turismo interior. La provincia de Albacete», Boletín de la Asociación de Geógrafos Españoles, 54, 361-383.

COMISIÓN EUROPEA (1999): ETE-Estrategia Territorial Europea. Hacia un desarrollo equilibrado y sostenible del territorio de la UE. Postdam.

FAYOS-SOLÁ, E. (1996): «Tourism policy: a midsummer night's dream?», Tourism Management, 17 (6), 405-412.

FERNÁNDEZ, A. (2004): «Turismo y Ordenación del Territorio», Quaderns de Política Econòmica, Segunda Época, nº 7, 35-47.

GRANADOS, V. (2008): «La gestión sostenible del territorio como elemento clave para el desarrollo turístico», en Actas de la Conferencia Internacional de Turismo: El conocimiento como valor diferencial de los productos turísticos. OMT. Málaga

JUNTA DE ANDALUCÍA. CONSEJERÍA DE TURISMO, COMERCIO Y DEPORTE (2007): Plan General de Turismo Sostenible de Andalucía (2008-2011). Sevilla. Junta de Andalucía.

JUNTA DE ANDALUCÍA. CONSEJERÍA DE TURISMO, COMERCIO Y DEPORTE (2008): Balance del año turístico en Andalucía 2007. Sevilla. Junta de Andalucía.

LAZZARETTI, M. y PETRILlO, E. (2006): Tourism Local Systems and Networking. Elsevier, Oxford. 
LENO, F. (1993): Técnicas de evaluación del potencial turístico. Madrid, Ministerio de Industria, Comercio y Turismo.

LEW, A.A. (1987): «A framework of tourist attraction research», Annals of Tourism Research, 14, 553-575.

LÓPEZ OLIVARES, D. (1998): La ordenación y la planificación integrada de los recursos territoriales turísticos. Castellón, Publicacions de la Universitat Jaume I.

LÓPEZ PALOMEQUE, F. (1998): «Cambios en la organización y política turísticas de Cataluña en los años noventa», en Foros sobre el Turismo entre España, Portugal e Iberoamérica: proximidad cultural y distancia geográfica. Cáceres, Asociación Española e Expertos Científicos en Turismo, $18 \mathrm{p}$.

LÓPEZ, J.M. y LÓPEZ, L.M. (2008): «La capacidad de carga turística: revisión crítica de un instrumento de medida de sostenibilidad», El Periplo Sustentable, 15, 123-150.

MARCHENA, M. (1989): «El turismo en España: razones de Estado, política regional y ordenación del territorio», Boletín Económico de ICE, núm. 2.197, 3.399-3.405.

MARCHENA, M. (1998): «Políticas de desarrollo de productos turísticos y estrategias de planificación del territorio», en Turismo y planificación del territorio en la España de fin de siglo, Actas de las V Jornadas de Geografía del Turismo, Universidad Rovira Virgili, Tarragona.

MERINERO, R. (2009): Las redes de actores en la gestión participativa del turismo en el ámbito local: el caso de las Ciudades Medias del interior de Andalucía. Modelos, estrategias y resultados. Sevilla. Consejería de Turismo, Comercio y Deporte de la Junta de Andalucía.

MICHAEL, E. (2007): Micro-Clusters and Networks: The Growth of Tourism. Elsevier. Oxford.

MONTESEIRÍN, O. (2008): «La convergencia entre el espacio y el producto turístico: de los Planes de Dinamización Turística a los Planes de Dinamización del Producto Turístico», en VERA, J.F. e IVARS, J.A. (Eds.): Espacios turísticos. Mercantilización, paisaje e identidad. Instituto Universitario de Investigaciones Turísticas. Universidad de Alicante. Alicante, 153-163.

OMT-WTO (2001): Cooperación entre sectores público y privado. Madrid. CEOMT.

OMT-WTO (2002): Guía para Administraciones Locales: Desarrollo Turístico Sostenible. Madrid. CEOMT.

PEARCE, D. (1997): «Tourism and the autonomous communities in Spain», Annals of Tourism Research, 21 (1), 156-177.

PFORR, C. (2006): «Tourism Policy in the Making. An Australian Network Study», Annals of Tourism Research, 33 (1), 87-108.

PULIDO, J.I. y LÓPEZ, Y. (2011): «Tourism: Analysis of a global phenomenon from a perspective of sustainability», en Pachura, P. (ed.): The systemic dimension of globalization. Croatia, InTech. Open Access Publisher, 267-288.

SÁEZ, A. (2008): «Los micro-clusters turísticos ¿Una herramienta para el desarrollo turístico en zonas rurales deprimidas? », Semestre Económico, 12 (24), 57-68.

SÁNCHEZ CUENCA, J. (1990): «La segmentación», en E. ORTEGA: Manual de investigación Comercial. Madrid. Pirámide.

SELIN, S. y CHAVEZ, D. (1995): «Developing an Evolutionary Tourism Partnerships Model», Annals of Tourism Research, 22 (4), 844-856. 
TROITIÑO, M.A. (1999): «El diagnóstico y la valorización del territorio», en GARCÍA, J.L. (ed.): Instrumentos para el desarrollo local. Excmo. Ayto. de Santa Cruz de Tenerife. Santa Cruz de Tenerife, 51-77.

VALENZUELA, M. (1986): «Turismo y territorio. Ideas para una revisión crítica y constructiva de las prácticas espaciales del turismo», Estudios Turísticos, 90, 47-56.

VALENZUELA, M. (2008): «Nuevos turismos para nuevos turistas. De la identificación a la captación de la clientela», en CEBRIÁN, F. (coord.): Turismo rural y desarrollo local. Cuenca. Servicio de Publicaciones Universidad de Castilla-La Mancha; Secretariado de Publicaciones Universidad de Sevilla, 57-65.

VERA, F. y ANTÓN, S. (1998): «Métodos y técnicas para la planificación turística del territorio», V Jornadas de Geografía del Turismo, Ocio y Recreación, A.G.E., Tarragona, 35-70.

VERA, J.F. (Coord.), LÓPEZ PALOMEQUE, F., MARCHENA, M. y ANTÓN, S. (1997): Análisis territorial del turismo. Barcelona. Ariel Geografía.

VERA, J.F. (Coord.), LÓPEZ PALOMEQUE, F., MARCHENA, M. y ANTÓN, S. (2011): Análisis territorial del turismo y planificación de destinos turísticos. Valencia. Tirant lo Blanch.

VERNON, N., ESSEX, S., PINDER, D. y CURRY, K. (2005): «Collaborative Policimaking. Local Sustainable Projects», Annals of Tourism Research, 32 (2), 325-345.

WILLIAMS, A.M. y SHAW, G. (1990): «Tourism research: a perspective», American Behavioural Scientist, 36, 133-143. 
